\title{
Searching nature-based solutions to emerging diseases: a preliminary review of Cameroonian medicinal plants with potentials for the management of COVID-19 pandemic
}

Evariste FONGNZOSSIE FEDOUNG ( $\square$ fongnzossie@gmail.com ) University of Douala

Achille BIWOLE University of Douala

Christine Fernande NYANGONO BIYEGUE University of Douala

Marlene NGANSOP

University of Yaounde 1

Patrick AKONO NTONGA

University of Douala

Damien Marie ESSONO University of Yaoundé 1

Forbi Preascious FUNWI University of Yaoundé 1

Calvin TONGA University of Douala

Guy Merlin NGUENANG University of Yaoundé 1

Victor Aimé KEMEUZE Millennium Ecologic Museum

Denis Jean SONWA

Center for International Forestry Research

Nole TSABANG

Cameroon Ethnobotany Network

ISabelle Sandrine BOUELET

University of Douala

\section{Zra TIZE}

University of Douala

Alexandre Teplaira BOUM

University of Douala 


\section{Marie Caroline MOMO SOLEFACK}

University of Dschang

Jean Kagarde BETTI

National Herbarium of Cameroon

Achille NOUGA BISSOUE

University of Douala

Leopold Gustave LEHMAN

University of Douala

Pierre Marie MAPONGMETSEM

University of Ngaoundéré

Annie NGONO NGANE

University of Douala

Jeanne NGOGANG YONKEU

Cameroon Academy of Science

\section{Systematic Review}

Keywords: COVID-19, medicinal plants, Ethnobotany, review, Cameroon

Posted Date: November 2nd, 2020

DOI: https://doi.org/10.21203/rs.3.rs-100548/v1

License: (c) (1) This work is licensed under a Creative Commons Attribution 4.0 International License. Read Full License 


\section{Searching nature-based solutions to emerging diseases: a preliminary}

review of Cameroonian medicinal plants with potentials for the management of COVID-19 pandemic

Fongnzossie Fedoung Evariste ${ }^{1,2,4,5^{*}}$, Biwole Achille Bernard ${ }^{1}$, Nyangono Biyegue Christine Fernande $^{2}$, Ngansop Tounkam Marlène ${ }^{3,4}$, Patrick Akono Ntonga ${ }^{6}$, Essono Damien Marie ${ }^{3}$, Forbi Preasious Funwi ${ }^{3,4}$, Tonga Calvin ${ }^{6}$, Nguenang Guy Merlin ${ }^{3,5}$, Kemeuze Victor ${ }^{4,5}$, Sonwa Denis Jean ${ }^{7}$, Tsabang Nole ${ }^{4,5}$, Isabelle Sandrine Bouelet ${ }^{2}$, Tize $\mathrm{Zra}^{2}$, Boum Alexandre Teplaira ${ }^{2}$, Momo Solefack Marie Caroline ${ }^{5,8}$ Betti Jean Lagarde ${ }^{9}$, Nouga Bissoue Achille ${ }^{2}$, Lehman Leopold Gustave ${ }^{6}$, Mapongmetsem Pierre Marie ${ }^{4,5}$, Ngono Ngane Annie ${ }^{10}$, Ngogang Yonkeu Jeanne ${ }^{5,11 ; 12}$

1. Laboratory of Forest Resources and Wood Valorization, University of Douala, PO Box. 1872 Douala, Cameroon

2. Laboratory of Process Engineering, University of Douala, PO Box. 1872 Douala, Cameroon

3. Laboratory of Botany, University of Yaoundé 1, PO Box 812 Yaoundé, Cameroon

4. Millenium Ecologic Museum, PO Box 8038 Yaoundé, Cameroon

5. Cameroon Ethnobotany Network. PO Box 8038 Yaoundé, Cameroon

6. Laboratory of Animal Biology, Department of Animal Biology, Faculty of Science, University of Douala, -P.O. Box 2701, Douala, Cameroon

7. Center for International Forestry Research, PO Box 2008, Messa, Yaoundé, Cameroon

8. Laboratory of Botany, University of Dschang. PO Box 67, Dschang, Cameroon

9. Laboratory of Plant Biology and Physiology, University of Douala. P.O. Box 24157, Douala, Cameroon

10.Laboratory of Biochemestry, University of Douala. PO Box 24157 Douala, Cameroon

11.Camerron Acadmy of Science

12.Université des Montagnes

Corresponding author: Fongnzossie Fedoung Evariste,' University of Douala, Advanced Technical Teacher's Training School for Technical Education, PO Box. 1872 Douala, Cameroon.Email:fongnzossie@gmail.com 


\begin{abstract}
Since the outbreak in December 2019 in Wuhan (China) of COVID-19, approved drugs are still lacking and the world is seeking effective treatment. The purpose of this article is to review the medicinal plants with potential to be used as complementary therapies against COVID-19. Bibliographic information was searched in several databases (Google Scholar, PubMed, Scopus, ScienceDirect, PROTA), to retrieve relevant papers on (1) plants used to manage common symptoms of COVI-19, (2) plant secondary metabolites with confirmed inhibitory effects on COVI-19 and (3) plants exhibiting pharmacological activities of relevance for COVID-19 management. A total of 230 species was recorded as potential source of ingredients for the fight against the 2019 novel corona virus. Of these species, 30 contain confirmed antiCOVID-19 secondary metabolites, 90 are used traditionally to manage at least 3 common symptoms of COVID-19, 10 have immunostimulant activity, 52 have anti-inflamatory activity, 14 have antiviral properties and 78 species are documented as used to treat malaria. A PCA analysis showing cluster formatting among the recorded species recorded indicates 4 groups of species and an array of possibility of using individual species or combination of species for their complementary effects. The authors argue that Cameroonian medicinal plants can be of potential contribution to the fight against COVID-19. Further applied research is needed to provide more scientific evidence for their efficacy, to establish standard formulations and clinical studies as part of efforts to develop therapies for COVID-19.
\end{abstract}

Key words: COVID-19, medicinal plants, Ethnobotany, review, Cameroon 


\section{Introduction}

\subsection{Background on the outbreak and epidemiology of COVID-19 pandemic}

Corona viruses are well known in veterinary medicine. First discovered in the 1960 s as parasites of infectious chicken bronchitis, they were later found to be responsible for serious epidemics in humans such as Severe Acute Respiratory Syndrome (SARS) in 2002/2003 and the Middle East Respiratory Syndrome (MERS) in 2012.

Huang et al. (2020) reported in late December 2019, an outbreak of a mysterious pneumonia of unknown cause in the Huanan Seafood Wholesale Market, in Wuhan, Hubei, China. The causal agent of this disease was isolated and identified by Chinese scientists as a new strain of Corona virus, the SARS-CoV-2 or 2019 novel corona virus (2019-nCov). Data obtained on patients with laboratory-confirmed 2019-nCoV infection in the hospital of Wuhan indicated that the common early symptoms of this disease were fever (98\% of patients), cough (76\%), and myalgia or fatigue $(44 \%)$. Complications associated with this disease as observed in hospitalized patients included acute respiratory distress syndrome (29\%), RNAaemia (15\%), acute cardiac injury $(12 \%)$ and secondary infections $(10 \%)$.

Because this 2019-nCov is spread by human-to-human transmission via droplets or direct contact (Lai et al., 2020), its emergence in China has caused a large global outbreak. According to the European Centre for Disease Prevention and Control, the situation update worldwide shows that since 31 December 2019 and as of 29 october 2020, a total of 44,574,981 cases of COVID-19 have been reported worldwide, including 1, 175, 279 deaths (ECDC, 2020). During the same period, African continent has reported 1,750,331 cases (21,793 cases reported for Cameroon and 426 deaths); the countries reporting most deaths being South Africa (19,111), Egypt (6,234), Morocco $(3,506)$, Algeria $(1,941)$ and Ethiopia $(1,451)$. 
Despite the ongoing efforts to manage the disease, no specific vaccine or antiviral drug currently exist for the prevention or treatment (Chen et al., 2020), or many months may be required for their development. However, the spread of the COVID-19 pandemic is very dynamic and growing around the world. In response to this outbreak, the World Health Organization, on January 30, 2020 declared that the pandemic constitutes a public health emergency of international concern and issued temporary recommendations under the International Health Regulations.

\subsection{Global therapeutic response to COVID-19}

Currently, no approved drug for COVID-19 exists and treatments provided worldwide to the affected persons are symptom based. These include antiviral drugs so far used against major groups of viruses like human immunodeficiency virus (HIV), herpes, hepatitis, influenza, SARS-CoV and MERS-CoV, antimalaria drugs, imunostimulants, anti-inflammatory drugs that may be effective against elevated levels of cytokines and useful in inhibiting viral infection (Vellingiri et al., 2020). A review by Vellingiri et al. (2020) and Liu et al. (2020) reported that the current most clinically used drugs include:

- Arbidol: a drug targeting $\mathrm{S}$ protein/ACE2, it is an inhibitor that may disrupt the binding of viral envelope protein to host cells, thus preventing viral entry to the target cell. It has been used earlier as influenza antiviral drug;

- Chloroquine/Hydroxychloroquine: anti-malarial drugs, which has been effective in the treatment of avian influenza $\mathrm{A}$ and has also shown to have anti-viral as well as immune modulating properties. It can elevate endosomal $\mathrm{pH}$ and consequently interfere with ACE2 glycosylation; 
- Favipiravir: broad spectrum anti-viral drug, this is a purine nucleoside whose possible mechanism on COVID-19 is through its action as an alternate substrate leading to inaccurate viral RNA synthesis;

- Lopinavir: a protease inhibitor that wa used along with another flu drug, oseltamivir and resulted in complete recovery of patients showing signs of COVID-19 related pneumonia;

- Nitazoxanide: drug so far used in various helminthic, protozoal, and viral infectioncaused diarrhea that may inhibit viral protein expression;

- Remidesivir: an anti-viral peptidewhich was used in treatments against Ebola, SARSCoV and MERS-CoV;

- Ribavirin : a broad-spectrum antiviral drug used in the treatment of hepatitis $\mathrm{C}$, in combination with interferon $\alpha($ IFN);

- Sofosbuvir: a drug also used for the treatment of hepatitis $\mathrm{C}$ in combination with interferon or RBV;

Worldwide, a number of drugs which have so far been proven to be safe for humans are currently being repurposed to be used for the management of this disease.

The 2019 novel coronavirus genome encodes several structural proteins, including the glycosylated spike (S) protein that functions as a major inducer of host immune responses. This $\mathrm{S}$ protein mediates host cell invasion via binding to a receptor protein called angiotensin-converting enzyme 2 (ACE2) located on the surface membrane of host cells. Hence, the interaction between viral S protein and ACE2 on the host cell surface is of significant interest in the therapeutic response process since it initiates the infection process. 


\subsection{Herbal medicine and the COVID-19 challenge: a global overview}

Globally, herbal treatments have been proven effective to control contagious disease during the 2003 severe acute respiratory syndrome (SARS) outbreak (Zhang et al., 2020). Therefore, since the outbreak of COVID-19, there has been great attention paid on investigating metabolites secreted by plants that may be developed as medicines for COVID-19.

Historically, traditional medicine and local beliefs have always played a role in situation of epidemics through times (Zhang, 1996). A review by Jassim and Navi (2003) reported numerous potentially useful medicinal plants that need to be evaluated and exploited for therapeutic applications against genetically and functionally diverse viruses' families. Keyaerts et al. (2007) identified a variety of plant lectins as antiviral compounds against the SARS-CoV. Lelesius et al. (2019) also showed that some extracts of plants including Thymus vulgaris and Desmiodium canadense were effective against avian infectious bronchitis virus, a highly contagious respiratory disease in chickens caused by a corona virus that belongs to the Coronaviridae family. From all over the world, people are witnessing a deep attachment to popular medicine to protect themselves against COVID-19.

Africa is endowed with diverse environmental conditions and a diversity of pathogenic microbes species (bacteria, fungi, and viruses), suggesting that African plants could accumulate chemopreventive substances more than plants from the northern hemisphere (Mahomoodally, 2013). Basically, more than $80 \%$ of the population in this continent is known to rely on traditional medicine for their primary health care needs. In Burkina faso, the country's plan to respond to the COVID-19 pandemic does not rule out the use of herbal medicines and clinical trials are underway on Apivirine, a 
phytomedicine from Benin which is alleged to be effective against the coronavirus (Sputniknews, 2020).

In Mexico, newspapers have reported the use of amulets to protect individuals from COVID-19 (Le Point International, 2020).

In Algeria, to face the spread of this pandemic, consultation of herbalists in the search of traditional antiviral and anti-flu recipes have significantly increased (Le Point International, 2020).

Goothy et al.(2020) supported the possible role of medicinal plants in Ayurveda's medicine for the management of Corona virus disease (COVID-19). Sharma and Kaur (2020) showed that Jensenone from Eucalyptus essential oil was a potential inhibitor of 2019 corona virus.

In China, DU Hong-Zhi, et al. (2020) argued that traditional chineese medicine is an effective treatment for 2019 novel coronavirus pneumonia.

More recently, the Malagasy Institute for Applied Research developed an herbal tea based on Artemisia annua (COVID Organics), claiming preventive and curative properties against COVID-19 (Midi-Madagascar, 2020).

In China, herbal traditional medicine have been proven effective to control contagious disease during the 2003 severe acute respiratory syndrome (SARS) outbreak and a recent screening of Chinese herbal medicine database have confirmed that herbal treatments classically used for treating viral respiratory infection contain chemical compounds that have potential anti-2019-nCoV activity (Zhang et al., 2020).

In Cameroon, since the first case was reported in the country, several herbal recipes have been popularized in social media as alledged solutions to manage COVID 19. According to a recent release from the Cameroon Radio and Television Corporation, the Archbishop of Douala, His grace Samuel Kleda has made public an attempt at 
treating symptoms of the COVID-19 with a herbal remedy, free of charge and the Ministry of public health is showing commitment to support the process of development and homologation of this treatment (Crtv, 2020).

As the world is currently seeking treatment for COVID-19, there is an urgent need to boost up research so as to develop effective and affordable therapeutics.

\subsection{Cameroon's response strategy to COVID-19}

In Cameroon, access to health care services is challenging. One out of every 1000 patients are able to see a specialist and 3 out of 20 patients are able to buy prescribed drugs in hospitals (Kuete and Efferth, 2010). In this context, the COVID-19 situation is likely to worsen as the country steped into phase 2 of this pandemic marked by a shift from virus importation to intra-community transmission. Based on this situation, the Government prepared a COVID-19 Preparedness and Response Plan of US\$ 600 million to respond to the crisis, under the leadership of the Ministry of Public Health and with the parthership of international organizations. This health response strategy has eight components:

- Multisectoral and international coordination,

- Surveillance for early detection of cases,

- Investigation and rapid intervention teams,

- Laboratory capacities,

- Infection prevention and control measures in hospitals and in the community,

- Cases management,

- Risk communication and Community engagement, and

- Logistics. 
Several treatment protocols including the Chloroquine-based treatment suggested by Professor Didier Raoult (Colson et al., 2020) are being tested with more or less mitigated results.

However, since the outbreak of this disease, ethnobotanical and ethnopharmacological research geared at bringing the potentials of traditional medical knowledge into the debate over the management of this disease has been lacking. Yet Cameroon is a biologically diversed Country. Located in Central Africa, at the heart of the Congo Basin, the second world-largest rainforest after the Amazon, its floristic potential scores more than 7850 plant species recorded at the national herbarium. This ranks Cameroon among the country with high level of biodiversity in Africa. Despite the inaccuracy of statistics, the medicinal plants are important elements of health care services. However, access to such plants has so far been largely through traditional healers and herbal markets which are part of an informal economy. The huge volume of published researches on medicinal plants in Cameroon surprisingly contrasts with the paucity of approved phytodrugs. The increasing use of traditional medicines, the general weakness in translating research into concrete drug discovery and development, the evolution of international regulations on access to genetic resources and the growing concern by stakeholders vis-à-vis the demands for patenting rights, evidence of safety, efficacy, good quality traditional medicinal products and a range of other ethical issues, the shortage of essential infrastructure in both the public (universities and other governmental institutions) and private sectors, compounded by the need for integrating and promoting the potential of medicinal plants as a source of health care are among the pressing challenges that must be tackled for acceptable use of traditional and alternative medicines in modern therapeutics in Cameroon. So far, there have been significant efforts within the framework of the Cameroon Ethnobotany 
Network and the Millennium Ecologic Museum, under the leadership of Late $\operatorname{Pr}$ Bernard-Aloys Nkongeneck, Pr Daniel Lantum Pr Jacques Kamsu Kom and Pr Jeanne Ngogang, towards the strengthening the capacity of Cameroonian traditional healers. Series of training were offered geared at improving their knowledge and practice on basic techniques of pharmaceutical sciences. Nowadays and more than ever, it is still an imperative to keep pace with the committments of these pioneering ethnobotanists and to continue adding efforts to boost research and development in the field of medicinal plants. As new and effective drugs are urgently needed, in the fight gainst COVID-19, research programs into alternative therapeutics including medicinal plants investigations need to be encouraged.

\subsection{Purpose of this review}

This review is part of the contribution of ethnobotany and ethnopharmacology aciences in the fight against the Covi-19. It aims at providing a preliminary review of available literature on medicinal plants with potentials to be evaluated and developed for the management of COVID-19 in Cameroon.

The findings of this review study will provide other researchers with opportunities to identify the right medicinal plants to be evaluated from a perspective of developing new drugs to combat COVID-19.

\section{Methodological approach}

\subsection{Theoretical framework to the selection of potential anti-COVID plants}

The theoretical framework for the study is based on a 3-steps review approach.

First, we acknowledge that the use of medicinal plants for the treatment of viral infections in our traditional societies is ancient. Meanwhile, COVID-19 is a novel 
disease and consequently not yet known in our traditional knowledge system on diseases. However, evidence from existing literature supports the management of symptoms similar to those of COVID-19 using a diversity of plant-based recipes. Recent review by Adhikari et al. (2020) presented the most commonly reported symptoms of COVID-19. Those considered in this review were: fever/malaria, runny nose, cough, myalgia or fatigue, body pains and sore throat. This review is based on the assumption that, a plant that has been used to manage at least 3 common symptoms of COVID-19 is a potential source of anti-COVI-19 molecules.

Secondly, the inhibitory effect of some secondary metabolites from medicinal plants on the 2019 novel corona virus protease have been reported by Zhang et al. (2020) in China, Mohammadi and Shaghaghi (2020) in Iran and Khaerunnisa et al. (2020) in Indonesia. In this regard, the identification of Cameroonian medicinal plants with potentials as antiCOVID-19 was based on the investigations on their phytochemical profile to select those that are source materials for these secondary metabolites. Besides the metabolites cited by the above-mentioned studies, alkaloids are also a rich source of active components of plants that have already been fruitfully developed into various chemotherapeutic compounds comprising Chloroquine, an antimalarial drug reported to be effective for the treatment of COVID-19 and many other viral infections (Moradi et al., 2017 ; Colson et al., 2020; Jianjun et al., 2020). The mechanism of the antiviral activity of alkaloids is based on the inhibition of replication of viruses. Hence, in this study, a plant known as important source of alkaloid is also considered as potential anti-COVID-19. Similar bioactivity on 2019-nCov was also reported for hydrolysable tannins, natural polyphénols (Khalifa et al., 2020; Adem et al., 2020) and terpenoids (Shagaghi, 2020). Therefore, we also consider of great potential for COVID-19 management plants that are rich sources of these secondary metabolites. 
Thirdly, the use of biologics that stimulate the immune responses was suggested by Zumla et al. (2020) as a way to help patients resist the invading virus. There is an abundant literature reporting the use of plants by traditional medicine practitioners to boost the immune system in people living with HIV/AIDS (Upoki Anywar et al., 2020). In addition to the important role of boosting the immune system, evidence from the literature reveal the importance of antimalaria and antiviral drugs in the global therapeutics against COVID-19 (Vellingiri et al., 2020). This is also the case for antiinflammatory drugs that may be effective against elevated levels of cytokines and useful in inhibiting viral infection. Hence, plants with immunostimulant, antiviral, anti-malaria and anti-inflammatory properties are considered in this study as of great potentials for COVID-19 management.

\subsection{Data collection and computation}

This review is based on data available in published literature. Bibliographic information on medicinal plants was searched in several databases including: Google Scholar, PubMed, Scopus, ScienceDirect, Researchgate, PROTA, GLOBEinMED, to retrieve all relevant papers. A total of 119 papers were reviewed including books, journal articles, proceedings, preprints. The reference lists of some research articles were exploited to explore additional relevant studies. The database of the Global biodiversity Information Facility (GBIF) was searched to confirm the occurrences and distribution of the plant species recorded.

From the ethnobotanical and ethnomedical literature consulted, plants were selected and recorded based on their uses (focus on plants used to treat symptoms of COVID19), their phytochemical composition (with focus onplants rich in alkaloids, tannins, terpenoids and phenolics), their pharmacological activity (focus on plants with anti- 
inflammatory, immunomodulatory, antimalarial and anti-viral properties). All the plant species recorded were compiled in and Excel database.

The documented uses of each plant, the presence or absence of the targeted secondary metabolites and their documented pharmacological activity were used to generate a new data set which was analyzed by principal component analysis (PCA) to detect cluster formatting and the patterns of variability present in the data sets of the medicinal plant species recorded.

\section{Findings and implication}

\subsection{Confirmed anti-COVID19 molecules and their source plants in Cameroon}

The main protease (Mpro)/chymotrypsin like protease (3CLpro) from 2019 novel corona virus, is reported to be a potential target for the inhibition of its replication ( $\mathrm{Lu}$, 2020). Khaerunnisa et al. (2020) showed that luteolin-7-glucoside, demethoxycurcumin, apigenin-7-glucoside, oleuropein, curcumin, catechin, and epicatechin-gallate appeared to have the best potential to act as COVID-19 Mpro inhibitors. Faheem Khan et al. (2020) showed that epigallocatechin gallate (EGCG), a major constituent of green tea (Camelia sinensis), was the lead compound that could fit well into the binding sites of docked proteins of SARS-CoV-2 and recommended this molecule as a drug candidate for the treatment of COVID-19.

Mohammadi and Shaghaghi (2020) reported that secondary metabolites including kaempferol, quercetin, luteolin-7-glucoside, demethoxycurcumin, naringenin, apigenin-7-glucoside, oleuropein, curcumin, catechin, epicatechin-gallate, zingerol, gingerol, and allicin were potential inhibitor candidates for COVID-19 Mpro, with Curcumin showing the strongest interaction with the protease enzyme of COVID_19. 
Recent study by Zhang et al. (2020) has identified several Chinese medicinal plants classified as antiviral/pneumonia-effective that directly inhibit the novel coronavirus, 2019-nCoV. The metabolites tested for this bioactivity were Betulinic acid, Coumaroyltyramine, Cryptotanshinone, Desmethoxyreserpine, Dihomo-c-linolenic acid, Dihydrotanshinone, Kaempferol, Lignan, Moupinamide, N-cis-feruloyltyramine, Quercetin, Sugiol, Tanshinone IIa.

Khalifa et al. (2020) showed that the Pedunculagin, tercatain, and punicalin, three hydrolysable tannins, successfully inhibit the protease enzyme of 2019 novel Corona Virus.

Adem et al. (2020) evaluated the efficacy of medicinal plant-based bioactive compounds against COVID-19 Mpro by molecular docking study. They concluded that natural polyphénols including hesperidin, rutin, diosmin, apiin, diacetylcurcumin, (E)1-(2-Hydroxy-4-methoxyphenyl)-3-[3-[(E)-3-(2-hydroxy-4-methoxyphenyl)-3-

oxoprop-1-enyl]phenyl]prop-2-en-1-one, and $\beta, \beta^{\prime}$-(4-Methoxy-1,3 phenylene)bis(2'hydroxy-4',6'-dimethoxyacrylophenone were effective inhinitors of this new Corona Virus.

From the research conducted by these authors, it is clear that Cameroonian medicinal plants can provide source materials for these secondary metabolites. The review of the phytochemical screening done on Cameroonian medicinal plant species shows that 32 species native or naturalized in Cameroon are source materials for most of the abovementioned secondary metabolites (tavle 1). There are also evidences from available literature indicating diverse pharmacological properties for these species including antimicrobial, antiviral, analgesic, antiinflammatry, antipyretic, antioxidant, etc. (table 1). Besides Curcumine from Tumeric (Curcuma loonga), some of those local plant species are interesting as they contain many of those active secondary metabolites. 
This is the case of Zanthoxyllum heitzii containing both Apigenin-7-glucoside and

Oleuropein, and Citrus spp, a rich source of Diosmin, Lignan, Naringenin and

Quercetin that showed high inhibitory effect on 2019 corona virus.

Table 1. Cameroonian or naturalized species containing secondary metabolites with confirmed inhibitory effect on COVID-19

\begin{tabular}{|c|c|c|c|}
\hline $\begin{array}{l}\text { Confirmed anti- } \\
\text { Civid19 } \\
\text { compounds* }\end{array}$ & $\begin{array}{l}\text { Source plants } \\
\text { in Cameroon }\end{array}$ & Other relevant literature evidence & Reference \\
\hline Allicin & Allium sativum & $\begin{array}{l}\text { - Strong antimicrobial activity } \\
\text { - Stimulates the activity of immune } \\
\text { cells, } \\
\text { - Inhibits the release of TNF } \alpha \text { - } \\
\text { dependent pro-inflammatory } \\
\text { cytokines } \\
\text { - Inhibits the migration of } \\
\text { neutrophilic granulocytes into } \\
\text { epithelia, which is a crucial process } \\
\text { during inflammation }\end{array}$ & $\begin{array}{l}\text { Mohammadi and } \\
\text { Shaghaghi (2020), } \\
\text { Borlinghaus et al. (2014) }\end{array}$ \\
\hline $\begin{array}{l}\text { Apigenin-7- } \\
\text { glucoside, }\end{array}$ & $\begin{array}{l}\text { Zanthoxyllum } \\
\text { heitzii }\end{array}$ & $\begin{array}{l}\text { - exert inhibitory effect on HL-60 } \\
\text { cells through the reactive oxygen } \\
\text { species (ROS) generation, loss of } \\
\text { mitochondrial membrane potential } \\
\text { and cell cycle destabilization }\end{array}$ & $\begin{array}{l}\text { Mohammadi and } \\
\text { Shaghaghi (2020), } \\
\text { Khaerunnisa et al. } \\
\text { (2020), } \\
\text { Pieme et al. (2014) }\end{array}$ \\
\hline \multirow[t]{5}{*}{ Catechin } & $\begin{array}{l}\text { Khaya } \\
\text { grandifoliola }\end{array}$ & $\begin{array}{l}\text { - } \mathrm{n} \text {-hexane extract, crude and } \\
\text { purified fractions are active } \\
\text { antimalarial activities } \\
\text { - contains ingredients that showed } \\
\text { intitro activity against hepatitis } \mathrm{C} \\
\text { virus }\end{array}$ & $\begin{array}{l}\text { Mohammadi and } \\
\text { Shaghaghi (2020), } \\
\text { Khaerunnisa et al. } \\
\text { (2020), Agbedahunsi et } \\
\text { al. (1998) }\end{array}$ \\
\hline & Cola nitida & - Antimicrobial and antiosydant & \multirow{3}{*}{$\begin{array}{l}\text { Niemenak et al. (2008) } \\
\text { Ngoupayo Joseph, et al. } \\
\text { (2018) }\end{array}$} \\
\hline & Cola acuminata & - Antimicrobial and antiosydant & \\
\hline & Cola anomala & - Antimicrobial & \\
\hline & $\begin{array}{l}\text { Laportea } \\
\text { aestuans }\end{array}$ & $\begin{array}{l}\text { - Antimicrobial effect of } \\
\text { crude extract }\end{array}$ & Mambe et al. (2016) \\
\hline \multirow[b]{3}{*}{ Coumaroyltyramine } & $\begin{array}{l}\text { Ochthocosmus } \\
\text { Africanus }\end{array}$ & - & $\begin{array}{l}\text { Tala Sipowo et al. } \\
(2017)\end{array}$ \\
\hline & $\begin{array}{l}\text { Solanum } \\
\text { melongena }\end{array}$ & - antipyretic and analgesic effect & $\begin{array}{l}\text { Sakah Kaunda and } \\
\text { Zhang (2019) } \\
\text { Mutalik et al. (2003) }\end{array}$ \\
\hline & $\begin{array}{l}\text { Solanum } \\
\text { torvum }\end{array}$ & $\begin{array}{l}\text { - An isoflavonoid sulfate and a } \\
\text { steroidal glycoside isolated from } \\
\text { the fruits exhibited antiviral } \\
\text { activity on herpes simplex virus } \\
\text { type } 1 \\
\text { - wide spectrum of antimicrobial } \\
\text { activities against human and } \\
\text { animal clinical isolates }\end{array}$ & $\begin{array}{l}\text { Zhang et al. (2020), } \\
\text { Damrongkiet et al. } \\
\text { (2002), Chah et al. } \\
(2000)\end{array}$ \\
\hline
\end{tabular}




\begin{tabular}{|c|c|c|c|}
\hline Curcumin & Curcuma longa & $\begin{array}{l}\text { - Curcumin has antioxidant, anti- } \\
\text { inflammatory, antiviral and } \\
\text { antifungal actions. Not toxic to } \\
\text { humans. } \\
\text { - curcumin also enhances immunity }\end{array}$ & $\begin{array}{l}\text { Mohammadi and } \\
\text { Shaghaghi (2020), } \\
\text { Shaghaghi (2020), } \\
\text { Khaerunnisa et al. } \\
\text { (2020), Akram et al. } \\
\text { (2010), Zorofchian } \\
\text { Moghadamtousi et al. } \\
\text { (2014) }\end{array}$ \\
\hline Desmethoxyreserpine & Rauwolfia sp. & $\begin{array}{l}\text { - it produces hypothermia, increased } \\
\text { salivation, miosis, and increased } \\
\text { gastric acid secretion. }\end{array}$ & $\begin{array}{l}\text { Zhang et al. (2020), } \\
\text { Khaerunnisa et al. } \\
\text { (2020), Packman et al. } \\
(2006)\end{array}$ \\
\hline \multirow{2}{*}{ Diosmin } & $\begin{array}{l}\text { Cissus } \\
\text { quadrangularis }\end{array}$ & $\begin{array}{l}\text { - antagonistic effect on the } \\
\text { biochemical mediators of } \\
\text { inflammation, antioxidant, } \\
\text { antimicrobial activity }\end{array}$ & Mishral et al. (2010), \\
\hline & Citrus sinensis & $\begin{array}{l}\text { - anti-inflammatory, } \\
\text { antihypertensive, antiviral } \\
\text { diuretic, analgesic and } \\
\text { hypolipidemic properties }\end{array}$ & $\begin{array}{l}\text { Tarkang et al. (2012) } \\
\text { Aboni et al. (2009) }\end{array}$ \\
\hline \multirow{3}{*}{ Epicatechin-gallate } & $\begin{array}{l}\text { Parkia } \\
\text { biglobosa }\end{array}$ & $\begin{array}{l}\text { - The leaf extract of P. biglobosa } \\
\text { contains biologically active } \\
\text { principles that are relevant in the } \\
\text { treatment of malaria } \\
\text { - Antidiarrhoeal and Antibacterial }\end{array}$ & $\begin{array}{l}\text { Kuete et al. (2018) } \\
\text { Tijani et al. (2009) } \\
\text { Modupe Builders et al. } \\
\text { (2009) }\end{array}$ \\
\hline & $\begin{array}{l}\text { Camellia } \\
\text { sinensis }\end{array}$ & $\begin{array}{l}\text { - Regular consumption of green tea } \\
\text { decreases influenza infection rates } \\
\text { and some cold symptoms, and that } \\
\text { gargling with tea catechins may } \\
\text { protect against the development of } \\
\text { influenza infection }\end{array}$ & $\begin{array}{l}\text { Mohammadi and } \\
\text { Shaghaghi }(2020) \text {, } \\
\text { Faheem Khan et al. } \\
(2020), \text { Khaerunnisa et } \\
\text { al. (2020), Isemura } \\
(2019)\end{array}$ \\
\hline & $\begin{array}{l}\text { Laportea } \\
\text { aestuans }\end{array}$ & $\begin{array}{l}\text { - Antimicrobial effect of } \\
\text { crude extract }\end{array}$ & Mambe et al. (2016) \\
\hline Gingerol & $\begin{array}{l}\text { Zingiber } \\
\text { officinale }\end{array}$ & $\begin{array}{l}\text { - Gingerols, in ginger root have been } \\
\text { shown to have chemopreventive } \\
\text { effects that have been associated } \\
\text { with their antioxidant and anti- } \\
\text { inflammatory activities }\end{array}$ & $\begin{array}{l}\text { Mohammadi and } \\
\text { Shaghaghi (2020), } \\
\text { Mehdi Sharifi-Rad et al. } \\
\text { (2017) }\end{array}$ \\
\hline \multirow[b]{3}{*}{ Hesperidin } & Acacia senegal & - Used in the management of cough & Mahomoodally (2013) \\
\hline & $\begin{array}{l}\text { Laportea } \\
\text { aestuans }\end{array}$ & $\begin{array}{l}\text { - Antimicrobial effect of } \\
\text { crude extract }\end{array}$ & \\
\hline & Citrus spp & $\begin{array}{l}\text { - Increases antioxidant defenses, } \\
\text { scavenges reactive oxygen species, } \\
\text { modulates immune system activity } \\
\text { - Dose-dependent inhibitory effect } \\
\text { against dengue virus, prevents } \\
\text { intracellular replication of } \\
\text { chikungunya virus, and inhibits } \\
\text { assembly and long-term production } \\
\text { of infectious hepatitis C virus } \\
\text { particles in a dose-dependent } \\
\text { manner }\end{array}$ & $\begin{array}{l}\text { Mohammadi and } \\
\text { Shaghaghi }(2020) \text {, } \\
\text { Salehi et al. (2019) } \\
\text { Azantsa Kingue et al. } \\
(2017)\end{array}$ \\
\hline
\end{tabular}




\begin{tabular}{|c|c|c|c|}
\hline \multirow[t]{4}{*}{ Kaempferol } & $\begin{array}{l}\text { Bryophyllum } \\
\text { pinnatum }\end{array}$ & $\begin{array}{l}\text { - Antimicrobial and antioxidant } \\
\text { activity }\end{array}$ & $\begin{array}{l}\text { Zhang et al. (2020), } \\
\text { Mohammadi and } \\
\text { Shaghaghi (2020), } \\
\text { Ndendoung Tatsimo et } \\
\text { al. (2012) }\end{array}$ \\
\hline & $\begin{array}{l}\text { Laportea } \\
\text { aestuans }\end{array}$ & $\begin{array}{l}\text { - Antimicrobial effect of } \\
\text { crude extract }\end{array}$ & Mambe et al. (2016) \\
\hline & $\begin{array}{l}\text { Tephrosia } \\
\text { preussii }\end{array}$ & - & $\begin{array}{l}\text { Mba Nguekeu et al. } \\
(2017)\end{array}$ \\
\hline & Senna alata & $\begin{array}{l}\text { - Treatment for Pulmonary Arterial } \\
\text { Hypertension diseases. }\end{array}$ & Rhazri et al. (2015) \\
\hline \multirow{3}{*}{ Lignan } & $\begin{array}{l}\text { Echinops } \\
\text { giganteus }\end{array}$ & - Antioxydants & Tene et al. (2004) \\
\hline & $\begin{array}{l}\text { Kigelia } \\
\text { africana }\end{array}$ & $\begin{array}{l}\text { - Anti-diarrheal, anti-malarial, } \\
\text { analgesic, anti-inflammatory ans } \\
\text { anti-microbial activity }\end{array}$ & $\begin{array}{l}\text { Zhang et al. (2020), } \\
\text { Sidjui Sidjui et al. } \\
\text { (2015) } \\
\text { Saini et al. (2009) }\end{array}$ \\
\hline & $\begin{array}{l}\text { Zanthoxylum } \\
\text { heitzii }\end{array}$ & -- & Ngouella et al. (1994) \\
\hline Luteolin-7-glucoside & $\begin{array}{l}\text { Capsicum } \\
\text { annuum }\end{array}$ & $\begin{array}{l}\text { - The extract exhibited a } \\
\text { considerable anti-HSV-1 and anti- } \\
\text { HSV-2 activities }\end{array}$ & $\begin{array}{l}\text { Mohammadi and } \\
\text { Shaghaghi (2020), } \\
\text { Khaerunnisa et al. } \\
(2020) \text {, Taghreed et al. } \\
(2017)\end{array}$ \\
\hline Naringenin & Citrus spp & $\begin{array}{l}\text { - Increases antioxidant defenses, } \\
\text { scavenges reactive oxygen species, } \\
\text { modulates immune system activity } \\
\text { - Dose-dependent inhibitory effect } \\
\text { against dengue virus, prevents } \\
\text { intracellular replication of } \\
\text { chikungunya virus, and inhibits } \\
\text { assembly and long-term production } \\
\text { of infectious hepatitis C virus } \\
\text { particles in a dose-dependent } \\
\text { manner }\end{array}$ & $\begin{array}{l}\text { Mohammadi and } \\
\text { Shaghaghi (2020), } \\
\text { Salehi et al. (2019) } \\
\text { Azantsa Kingue et al. } \\
\text { (2017) }\end{array}$ \\
\hline $\begin{array}{l}\text { N-cis- } \\
\text { feruloyltyramine, }\end{array}$ & $\begin{array}{l}\text { Hibiscus } \\
\text { esculentus }\end{array}$ & - Antioxidant & Maganha et al. (2010) \\
\hline Oleuropein, & $\begin{array}{l}\text { Zanthoxylum } \\
\text { heitzii }\end{array}$ & - cancer prevention & $\begin{array}{l}\text { Mohammadi and } \\
\text { Shaghaghi (2020), } \\
\text { Khaerunnisa et al. } \\
\text { (2020), } \\
\text { Farooqi et al. (2017) }\end{array}$ \\
\hline Pedunculagin & Phyllantus spp & $\begin{array}{l}\text { - Antiviral, antimicrobial, anticancer, } \\
\text { hepatoprotective and anti diabetic }\end{array}$ & Shakya (2016) \\
\hline \multirow{3}{*}{ Punicalin } & $\begin{array}{l}\text { Terminalia } \\
\text { catappa }\end{array}$ & $\begin{array}{l}\text {-, a plant used to treat dermatitis and } \\
\text { hepatitis } \\
\text { - Antiinflamatory activity }\end{array}$ & Mohale et al. (2009) \\
\hline & $\begin{array}{l}\text { Combretum } \\
\text { glutinosum }\end{array}$ & $\begin{array}{l}\text { - Methanolic and water extract from } \\
\text { leaves and stem bark have } \\
\text { Antimicrobial activity }\end{array}$ & $\begin{array}{l}\text { Jossang et al. } \\
\text { (1994)Alowanou et al. } \\
(2015)\end{array}$ \\
\hline & $\begin{array}{l}\text { Terminalia } \\
\text { ivorensis }\end{array}$ & $\begin{array}{l}\text { - anti-inflammatory, antioxidant and } \\
\text { anti-HIV activities }\end{array}$ & $\begin{array}{l}\text { Assamoi Adiko et al. } \\
(2013)\end{array}$ \\
\hline
\end{tabular}




\begin{tabular}{|c|c|c|c|}
\hline & $\begin{array}{l}\text { Morinda } \\
\text { morindoides }\end{array}$ & $\begin{array}{l}\text { - leaves exhibited antispasmodic } \\
\text { effect }\end{array}$ & Mamadoul et al. (2011) \\
\hline Quercetin & Citrus limon & $\begin{array}{l}\text { - Treatment of chronic pneumonia } \\
\text { (naringenin) } \\
\text { - Inhibition of cytokine production; } \\
\text { - Inhibition of inflammation } \\
\text { mediator (D-limonene) } \\
\text { - Inhibition of the virus Herpes } \\
\text { simplex. }\end{array}$ & $\begin{array}{l}\text { Zhang et al. (2020), } \\
\text { Mohammadi and } \\
\text { Shaghaghi }(2020) \text {, } \\
\text { Klimek-Szczykutowicz } \\
\text { et al (2020) }\end{array}$ \\
\hline
\end{tabular}

* Based on the studies by Khaerunnisa et al. (2020), Faheem Khan et al. (2020), Shagaghi (2020), Mohammadi and Shaghaghi (2020, Zhang et al. (2020), Khalifa et al. (2020) and Adem et al. (2020)

\subsection{Cameroonian medicinal plant used to manage symptoms of COVID 19}

The review yielded a total of 230 medicinal plants of potential for the management of COVID-19. From this general list of plants recorded, 90 species were selected for being mentioned as used to manage at least 3 symptoms of Covi-19, and the remaining species were excluded (Table 3). These 90 species belongs to 53 botanical families. The families with the greatest number of representatives are Rubiaceae ( 8 species), Asteraceae and Euphorbiaceae (6 species), Caesalpiniaceae and Meliaceae (5 species),

Solanaceae (4 species), Apocynaceae, Combretaceae, Malvaceae, Sapotaceae and Verbenaceae (3 species).

The greatest number of citations was recorded for three of the six symptoms investigated: fever/malaria, cough and myalgia/fatigue (Table 2).

Table 2. Number of medicinal plants cited in the treatment of COVID-19 symptoms

\begin{tabular}{|l|c|c|}
\hline Symptoms & Number of plants recorded & Percentage \\
\hline Catarrh/Runny nose & 20 & 3.8 \\
\hline Cough & 138 & 26.3 \\
\hline Fever & 241 & 45.9 \\
\hline Myalgia/fatigue & 106 & 20.2 \\
\hline Headache & 8 & 1.5 \\
\hline Pains & 4 & 1.58 \\
\hline Sore throat & 3 & 0.6 \\
\hline
\end{tabular}


Various plant parts are used in the different treatments reported in the literature. However, leaves, fruits and barks were the most used parts, indicating that their utilization may not severely affect the sustainability of the resource base.

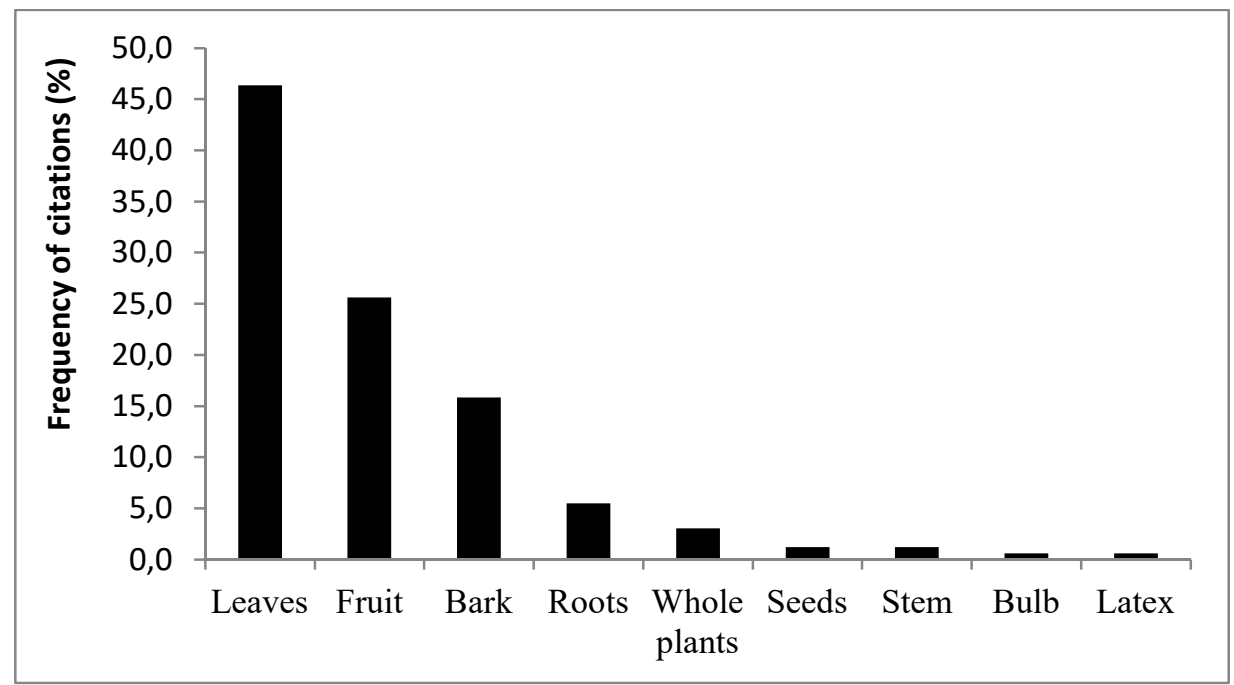

Figure 1. Frequency of plant parts used in management of COVID-symptoms

Available data on the phytochemical screening of these selected species shows that the most distributed secondary metabolite in this selected sample of plants was alkaloids (36\%) (figure2). Previous studies by Ntié Kang et al (2013) also confirmed the greater distribution of terpenoids (26\%), flavonoids (19.6\%) and alkaloids (11.2\%) in Cameroon's medicinal plants.

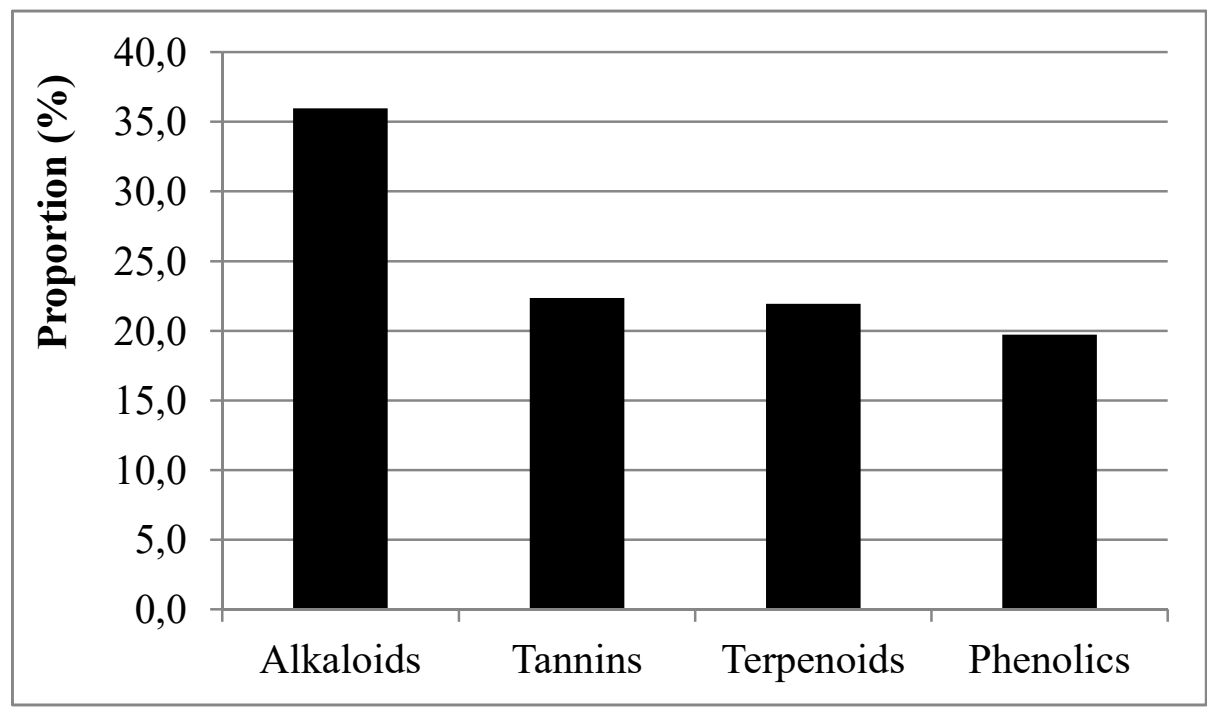

Figure 2. Distribution of secondary metabolites in the recorded plants 
Table 3. Cameroonian medicinal plant species used to manage at least 3 COVID 19 symptoms

\begin{tabular}{|c|c|c|c|c|c|}
\hline Species & Family & Part used ${ }^{*}$ & \begin{tabular}{|l|} 
Symptoms \\
treated
\end{tabular} & $\begin{array}{l}\text { Main } \\
\text { phytochemicals }\end{array}$ & Reference \\
\hline Abelmoschus esculentus & Sterculiaceae & $\mathrm{L}, \mathrm{Fr}$ & $\begin{array}{l}\text { Cough, Fever, } \\
\text { Myalgia }\end{array}$ & Tan, Phen, Terp & $\begin{array}{l}\text { Bogninou et al. ( 2018) Tomar (2017), Alamgeer et al. } \\
(2018)\end{array}$ \\
\hline Acanthus montanus & Acanthaceae & L & $\begin{array}{l}\text { Cough, Fever, } \\
\text { Myalgia }\end{array}$ & Alk & $\begin{array}{l}\text { Asongalem et al. (2004), Kuete and Efferth ( 2010), } \\
\text { Etame et al. (2018), Fongod et al. (2013) }\end{array}$ \\
\hline Adansonia digitata & Bombacaceae & $\mathrm{Bk}$ & $\begin{array}{l}\text { Cough, Fever, } \\
\text { Myalgia }\end{array}$ & Alk & $\begin{array}{l}\text { Yinyang et al. (2014), Arbonier (2019), Kamatou et al. } \\
\text { (2011). }\end{array}$ \\
\hline Ageratum conyzoides & Asteraceae & $\mathrm{L}$ & $\begin{array}{l}\text { Cough, Myalgia, } \\
\text { fever }\end{array}$ & Alk, Terp & $\begin{array}{l}\text { Ming (1999), Jiofack et al. (2008), Yinyang et al. } \\
\text { (2014) }\end{array}$ \\
\hline Alchornea cordifolia & Euphorbiaceae & $\mathrm{L}$ & $\begin{array}{l}\text { Cough, Fever, } \\
\text { Myalgia }\end{array}$ & Alk, Tan, Phen & Ngaha et al. (2016), Ngoupayo et al. (2015) \\
\hline Allium sativum & Liliaceae & Bulb & $\begin{array}{l}\text { Cough, Fever, } \\
\text { Myalgia }\end{array}$ & Alk & Papu et al. (2014), Khodadadi (2015) \\
\hline Aloe vera & Aloaceae & $\mathrm{L}$ & $\begin{array}{l}\text { Cough, Fever, } \\
\text { Myalgia }\end{array}$ & Alk & Pankaj et al. (2013), Yinyang et al. (2014), \\
\hline Alstonia boonei & Sapotaceae & Bk, Lx, L & $\begin{array}{l}\text { Cough, Fever, } \\
\text { Myalgia }\end{array}$ & Alk, Tan, Terp & Jiofack et al. (2008 \& 2009), Dibong et al. (2015) \\
\hline Amaranthus hybridus & Amaranthaceae & $\mathrm{Wp}$ & $\begin{array}{l}\text { Cough, Fever, } \\
\text { Myalgia }\end{array}$ & Alk, Terp & $\begin{array}{l}\text { Ouedraogo et al. (2012), Tinitana et al. (2016), Etame } \\
\text { et al. (2018) }\end{array}$ \\
\hline Ananas comosus & Annonaceae & Epc & $\begin{array}{l}\text { Cough, Fever, } \\
\text { Myalgia }\end{array}$ & Alk & Hossain1 et al. (2015), Yinyang et al. (2014) \\
\hline Anickia chloranta & Annonaceae & $\mathrm{Bk}$ & $\begin{array}{l}\text { Cough, Fever, } \\
\text { Myalgia }\end{array}$ & Alk, Phen, Tan & $\begin{array}{l}\text { Mekou et al. (2015), (Etame et al., 2018), Njayou et al. } \\
(2008)\end{array}$ \\
\hline Annona senegalensis & Annonaceae & Bk & $\begin{array}{l}\text { Cough, Fever, } \\
\text { Myalgia }\end{array}$ & Phen, Tan & Tsabang et al. (2012), Njayou et al. (2008) \\
\hline Annona muricata & Annonaceae & $\begin{array}{l}\text { L, Fr, Se, } \\
\text { Pulp }\end{array}$ & $\begin{array}{l}\text { Cough, Fever, } \\
\text { pains, catharrh }\end{array}$ & Alk, Tan & $\begin{array}{l}\text { Zorofchian Moghadamtousi et al.. (2015), Yinyang et } \\
\text { al. ( 2014), Tsobou et al. (2015) }\end{array}$ \\
\hline Anogeissus leiocarpus & Combretaceae & $\mathrm{Bk}$ & $\begin{array}{l}\text { Cough, Fever, } \\
\text { body pains }\end{array}$ & Tan & Ahmad (2014), Ndjonka et al. (2008) \\
\hline Anthocleista djalonensis & Loganiaceae & Bk & $\begin{array}{l}\text { Cough, Fever, } \\
\text { Myalgia }\end{array}$ & Alk, Phen, Tan & Bassey at al. (2009), Leke et al. (2012) \\
\hline Anthocleista nobilis & Loganiaceae & $\mathrm{Bk}$ & $\begin{array}{l}\text { Cough, Fever, } \\
\text { Myalgia }\end{array}$ & Alk, Phen, Tan, Ter & Mosango (2007), Sima et al. (2015) \\
\hline
\end{tabular}




\begin{tabular}{|c|c|c|c|c|c|}
\hline Artemisia аппиа & Asteraceae & Wp & $\begin{array}{l}\text { Cough, Fever, } \\
\text { Myalgia }\end{array}$ & Phen & $\begin{array}{l}\text { Jiofack et al. (2008), Iqbal et al. (2012), Sadiq et al. } \\
\text { (2014) }\end{array}$ \\
\hline Azadirachta indica & Meliaceae & Se, L, Bk & $\begin{array}{l}\text { Cough, Fever, } \\
\text { Myalgia }\end{array}$ & Alk, Phen, Tan, Ter & Jiofack et al. $(2009,2008)$, Dash et al. (2017) \\
\hline Brassica oleracea & Brassicaceae & $\mathrm{L}$ & $\begin{array}{l}\text { Cough, Fever, } \\
\text { Myalgia Sore } \\
\text { throat }\end{array}$ & Alk & Yinyang et al. (2014) \\
\hline Bridelia ferruginea & Euphorbiaceae & Bk & $\begin{array}{l}\text { Cough, Fever, } \\
\text { Myalgia }\end{array}$ & Alk, Tan, Terp & $\begin{array}{l}\text { Ndam et al. (2014), Jose and Kayode (2009), } \\
\text { Olumayokun et al. (2012) }\end{array}$ \\
\hline Bridelia micrantha & Euphorbiaceae & Bk & $\begin{array}{l}\text { Cough, Fever, } \\
\text { Myalgia }\end{array}$ & Alk, Phen, Tan, Ter & Arbonnier (2019), Etono et al. (2019), Maroyi (2017) \\
\hline Camellia sinensis & Theaceae & $\mathrm{L}$ & $\begin{array}{l}\text { Cough, Fever, } \\
\text { Myalgia }\end{array}$ & Alk & $\begin{array}{l}\text { Yinyang et al. (2014), Namukobea et al. (2011), } \\
\text { Sharangi (2009) }\end{array}$ \\
\hline Capsicum аппиит & Solanaceae & $\mathrm{L}, \mathrm{Fr}$ & $\begin{array}{l}\text { Cough, Headache, } \\
\text { Myalgia }\end{array}$ & Alk & Salehia et al. (2018), Yinyang et al. (2014) \\
\hline Capsicum frutescens & Solanaceae & $\mathrm{L}, \mathrm{Fr}$ & $\begin{array}{l}\text { Cough, Headache, } \\
\text { Myalgia }\end{array}$ & Alk, Terp & Salehia et al. (2018), Noumedem et al. (2013) \\
\hline Carica papaya & Cacicaceae & L, Fr & $\begin{array}{l}\text { Cough, Fever, } \\
\text { Myalgia }\end{array}$ & Alk, Tan, Terp & SIvarajah (2015), Sebua and Maroyi (2013) \\
\hline Catharanthus roseus & Apocynaceae & $\mathrm{L}$ & $\begin{array}{l}\text { Cough, Sorethroat, } \\
\text { Myalgia }\end{array}$ & Alk & Das and Sharangi (2017), Yinyang et al. (2014) \\
\hline Chromolaena odorata & Asteraceae & $\mathrm{L}$ & $\begin{array}{l}\text { Cough, Fever, } \\
\text { Myalgia }\end{array}$ & Alk, Tan, Terp & Vaisakh et Pandey (2012), Tamo et al. (2016), \\
\hline Cinchona calisaya & Rubiaceae & $\begin{array}{l}\text { B, Rt, L, } \\
\text { Fr }\end{array}$ & $\begin{array}{l}\text { Cough, Fever, } \\
\text { Myalgia }\end{array}$ & Alk & Eyal (2018), Yinyang et al. (2014) \\
\hline Cinchona officinalis & Rubiaceae & $\begin{array}{l}\text { B, Rt, L, } \\
\text { Fr }\end{array}$ & $\begin{array}{l}\text { Cough, Fever, } \\
\text { Myalgia }\end{array}$ & Alk & Eyal (2018), Yinyang et al. (2014) \\
\hline Cinchona pubescens & Rubiaceae & $\begin{array}{l}\text { B, Rt, L, } \\
\text { Fr }\end{array}$ & $\begin{array}{l}\text { Cough, Fever, } \\
\text { Myalgia } \\
\text { Headache, colds, }\end{array}$ & Alk & Eyal (2018), Yinyang et al. (2014) \\
\hline Citrus aurantifolia & Rutaceae & L, Fr & $\begin{array}{l}\text { coughs, sore } \\
\text { throats }\end{array}$ & Alk & Enejoh et al. (2015), Yinyang et al. (2014) \\
\hline Cochlospermum planchonii & Cochlospermaceae & L, Fr & $\begin{array}{l}\text { Cough, Fever, } \\
\text { Myalgia }\end{array}$ & $\begin{array}{l}\text { Alk, Phen, Tan, } \\
\text { Terp }\end{array}$ & $\begin{array}{l}\text { Isah et al. (2013), Usman et al. (2013), Mamidou Koné } \\
\text { et al. (2005) }\end{array}$ \\
\hline Cola acuminata & Malvaceae & L, Fr & Cough, Fever, & Alk, Phen & Otoide and Olanipekun (2018), Tchuenguem et al. \\
\hline
\end{tabular}




Cola nitida
Combretum micranthum
Costus afer
Crossopteryx febrifuga
Curcuma longa
Cymbopogon citratus
Diospyros mespiliformis
Dissotis rotundifolia
Eleusine indica
Emilia coccinea
Eremomastax speciosa
Eucalyptus camaldulensis
Euphorbia hirta
Eurycoma longifolia
Faidherbia albida
Garcinia cola

\begin{tabular}{|c|c|c|c|}
\hline & & Myalgia & \\
\hline Malvaceae & L, Fr & $\begin{array}{l}\text { Headache, Fever, } \\
\text { Myalgia }\end{array}$ & Alk \\
\hline Combretaceae & $\mathrm{L}$ & $\begin{array}{l}\text { Catarrh, Cough, } \\
\text { Fever, Myalgia }\end{array}$ & Alk, Terp \\
\hline Costaceae & St & $\begin{array}{l}\text { Catarrh, Cough, } \\
\text { Fever, Myalgia }\end{array}$ & Phen \\
\hline Rubiaceae & L, Fr & $\begin{array}{l}\text { Cough, Fever, } \\
\text { Myalgia }\end{array}$ & Alk \\
\hline Zingiberaceae & $\mathrm{Rz}$ & $\begin{array}{l}\text { Cough, Fever, } \\
\text { Myalgia }\end{array}$ & Terp \\
\hline Poaceae & $\mathrm{L}$ & $\begin{array}{l}\text { Cough, Fever, } \\
\text { Headache, Sore } \\
\text { throat, Myalgia }\end{array}$ & Alk, Terp \\
\hline Ebenaceae & L, Fr & $\begin{array}{l}\text { Cough, Fever, } \\
\text { Myalgia }\end{array}$ & Alk, Phen, Tan \\
\hline Melastomataceae & $\mathrm{L}$ & $\begin{array}{l}\text { Catarrh, Cough, } \\
\text { Fever, Myalgia }\end{array}$ & Alk, Phen, Tan \\
\hline Poaceae & Wp & $\begin{array}{l}\text { Cough, Fever, } \\
\text { Myalgia }\end{array}$ & Alk \\
\hline Asteraceae & Wp & $\begin{array}{l}\text { Cough, Fever, } \\
\text { Myalgia }\end{array}$ & Alk, Tan, Terp \\
\hline Acanthaceae & $\mathrm{L}$ & $\begin{array}{l}\text { Catarrh, Cough, } \\
\text { Fever, Myalgia, } \\
\text { Pains }\end{array}$ & Alk, Tan, Terp \\
\hline Myrtaceae & $\begin{array}{l}\text { L, Fr, Bk, } \\
\text { Rt }\end{array}$ & $\begin{array}{l}\text { Cough, Fever, } \\
\text { Myalgia }\end{array}$ & $\begin{array}{l}\text { Alk, Tan, Phen, } \\
\text { Terp }\end{array}$ \\
\hline Euphorbiaceae & Wp & $\begin{array}{l}\text { Cough, Fever, } \\
\text { Myalgia }\end{array}$ & Alk, Tan, Terp \\
\hline Simaroubaceae & L, Fr & $\begin{array}{l}\text { Cough, Fever, } \\
\text { Myalgia }\end{array}$ & Alk, Terp \\
\hline Mimosaceae & $\mathrm{Bk}$ & $\begin{array}{l}\text { Cough, Catarrh, } \\
\text { Fever }\end{array}$ & $\begin{array}{l}\text { Alk, Tan, Terp, } \\
\text { Phen }\end{array}$ \\
\hline Clusiaceae & $\mathrm{Fr}$ & Cough, Fever, & Alk \\
\hline
\end{tabular}

(2017), Yinyang et al. (2014), Lowe et al. (2014)

Olukayode et al. (2017), Yinyang et al. (2014)

Welch (2010), Chinsembu and Hedimbi (2010),

Yinyang et al. (2014), Dawe et al. (2013)

Boison et al. (2019), Tchuenguem et al. (2017)

Salawu et al. (2008), Arbonier (2019), Maiga et al. (2006)

Velayudhan et al. (2012), Gardini et al. (2009)

Etame et al. (2018), Yemele et al. (2014), Yinyang et al. (2014), Shah et al. (2011)

Hegazy et al. (2019), Ahmed and Mahmud (2017)

Jiofack et al. (2009), Yinyang et al. (2014), Yeboah and Osafo (2017)

Etame et al. (2018), Pattanayak and Maity (2017), Sagnia et al. (2014), Jiofack et al. (2008),

Nwachukwu et al. (-2017), Tsobou et al. (2015),

Jiofack et al. (2008), Tsobou et al. (2015), Sagnia et al. (2014)

Jiofack et al. (2008), Sani et al. (2014)

Tamo et al. (2016), Kumar et al. (2010)

Norhidayah Mohamed et al. (2015), Mohamad et al. (2010)

Ismail et al. (2014), Arbonier (2019), Marwa et al. (2018)

Jiofack et al. (2008 \& 2009), Betti (2002), Yinyang et 


\begin{tabular}{|c|c|c|c|c|}
\hline Guiera senegalensis & Combretaceae & $\mathrm{L}$ & $\begin{array}{l}\text { Myalgia } \\
\text { Cough, Fever, } \\
\text { Myalgia }\end{array}$ & $\begin{array}{l}\text { Alk, Tan, Phen, } \\
\text { Terp }\end{array}$ \\
\hline Harungana madagascariensis & Hypericaceae & $\mathrm{Bk}$ & $\begin{array}{l}\text { Cough, Fever, } \\
\text { Myalgia }\end{array}$ & Alk, Phen \\
\hline Hibiscus sabdarifa & Malvaceae & $\mathrm{L}$ & $\begin{array}{l}\text { Cough, Fever, } \\
\text { Myalgia }\end{array}$ & Alk \\
\hline Holarrhena floribunda & Apocynaceae & Bk, L & $\begin{array}{l}\text { Cough, Fever, } \\
\text { Myalgia }\end{array}$ & Alk \\
\hline Hoslundia opposita & Lamiaceae & Rt & $\begin{array}{l}\text { Cough, Fever, } \\
\text { Sore throat }\end{array}$ & Phen, Tan \\
\hline Hymenocardia acida & Euphorbiaceae & L, Rt & $\begin{array}{l}\text { Cough, Fever, } \\
\text { Myalgia }\end{array}$ & Terp \\
\hline Jatropha curcas & Euphorbiaceae & L & $\begin{array}{l}\text { Cough, Fever, } \\
\text { Headache } \\
\text { Cough, Fever, }\end{array}$ & Alk, Phen \\
\hline Kalenchoe crenata & Crassulacées & L & $\begin{array}{l}\text { Headache, } \\
\text { Myalgia }\end{array}$ & Alk, Terp \\
\hline Khaya senegalensis & Meliaceae & L, Fr & $\begin{array}{l}\text { Cough, Fever, } \\
\text { Myalgia }\end{array}$ & $\begin{array}{l}\text { Alk, Phen, Tan, } \\
\text { Terp }\end{array}$ \\
\hline Lantana camara & Verbenaceae & $\mathrm{L}$ & $\begin{array}{l}\text { Cough, Fever, } \\
\text { Catarrh }\end{array}$ & Alk, Tan, Terp \\
\hline Lippia multiflora & Verbenaceae & $\mathrm{L}$ & $\begin{array}{l}\text { Cough, Fever, } \\
\text { Catarrh }\end{array}$ & Tan, Terp \\
\hline Mangifera indica & Anacardiaceae & $\mathrm{Bk}$ & $\begin{array}{l}\text { Cough, Fever, } \\
\text { Catarrh }\end{array}$ & Alk, Terp \\
\hline Maytenus senegalensis & Celastraceae & $\mathrm{L}$ & $\begin{array}{l}\text { Catarrh, Cough, } \\
\text { Fever }\end{array}$ & Phen, Tan \\
\hline Melissa officinalis & Lamiaceae & L, Fr & $\begin{array}{l}\text { Catarrh, Cough, } \\
\text { Fever }\end{array}$ & Alk \\
\hline Milicia excelsa & Moraceae & Bk & $\begin{array}{l}\text { Catarrh, Cough, } \\
\text { Fever }\end{array}$ & Alk, Phen, Tan \\
\hline Mitragyna inermis & Rubiaceae & $\begin{array}{l}\text { L, Bk, } \\
\text { Rbk }\end{array}$ & $\begin{array}{l}\text { Catarrh, Cough, } \\
\text { Fever }\end{array}$ & $\begin{array}{l}\text { Alk, Phen, Tan, } \\
\text { Terp }\end{array}$ \\
\hline
\end{tabular}

al. (2014)

Shafei et al. (2016), Arbonier (2019), Somboro et al. (2011)

Nimenibo-Uadia and Nwachukwu (2017), Ndam et al. (2014)

Suresh and Ammaan (2017), Yinyang et al. (2014)

Hoekou et al. (2017), Yinyang et al. (2014)

Arbonier (2019), Sadri (2017), Ndjonka et al. (2008)

Amoa Onguéné et al. (2013), Tor-Anyiin Terrumun et al. (2013)

Arbonier (2019), Abdelgadir and Van Staden (2013), Oskoueian et al. (2011)

Yinyang et al. (2014), Jiofack et al. (2008), Nguelefack et al. (2006)

Chukwudi Ugoh et al. (2014), Arbonier (2019), Makut et al. (2008)

Tsobou et al. (2015), Kalita et al. (2012)

Gandonou et al. (2017), Djengue et al. (2017)

Mahalik et al. (2020), Yemele et al. (2014), Yinyang et al. (2014)

Arbonier (2019), Zangueu et al. (2018), Veloso et al. (2017)

Miraj et al. (2017), Yinyang et al. (2014)

Jiofack et al. (2008), Betti (2002), Akinpelu et al. (2020)

Mahougnan Toklo et al. (2020), Arbonier (2019), Konkon et al. (2008) 


Momordica charantia
Morinda lucida
Myristica fragrans
Olax subscorpioidea
Paullinia pinnata
Pavetta crassipes
Picralima nitida
Piliostigma thonningii
Sarcocephalus latifolius
Senna alata
Senna occidentalis
Senna sieberiana
Solanum nigrum
Solanum torvum
Spathodea campanulata
Terminalia laxiflora
Trema orientalis

\begin{tabular}{l|l} 
Cucurbitaceae & L \\
Rubiaceae & L, Fr \\
Myristicaceae & L, Fr \\
Olacaceae & L, Fr \\
Spindaceea & L, Rt \\
Rubiaceae & L, Fr \\
Apocynaceae & Fr, Rt \\
Caesalpiniaceae & L, Fr \\
Rubiaceae & Bk, L, Fr \\
Caesalpiniaceae & L, Fr \\
Caesalpiniaceae & L, Fr \\
Caesalpiniaceae & L, Fr \\
Solanaceae & L, Fr \\
Solanaceae & L \\
Bignoniaceae & Bk, L \\
Combretaceae & L, Fr \\
Ulmaceae & L, Fr
\end{tabular}

\begin{tabular}{|l} 
Cough, Fever, \\
Pains \\
Cough, Fever, \\
Pains \\
Catarrh, Fever, \\
Myalgia \\
Cough, Fever, \\
Myalgia \\
Cough, Fever, \\
Myalgia \\
Cough, Fever, \\
Myalgia \\
Cough, Fever, \\
Myalgia \\
Cough, Fever, \\
Sore Throat \\
Cough, Fever, \\
Myalgia \\
Cough, Fever, \\
Myalgia \\
Cough, Fever, \\
Myalgia \\
Headache, Fever, \\
Myalgia \\
Cough, Fever, \\
Myalgia \\
Cough, Fever, \\
Myalgia \\
Cough, Fever, \\
Myalgia \\
Cough, Fever, \\
Myalgia \\
Cough, Fever, \\
Myalgia \\
\end{tabular}

Alk, Phen, Tan, Terp

Tan

Alk, Phen,Terp,

Alk, Phen, Tan, Terp

Alk, Tan, $\mathrm{Ph}$

Alk, Phen

Alk, Tan, Terp

Phen, Tan

Ter, Phen

Alk, Tan

Alk, Phen, Tan, Terp

Alk, Phen, Tan

Alk, Terp

Alk, Phen, Tan

Terp

Alk, Phen, Tan, Terp

Alk, Phen, Tan, Ter Akin et al. (2016), Adinortey et al. (2013)

Jiofack et al. (2009), Mozaniel et al. (2018)

Adeleye and Ajamu (2018), Ndam et al. (2014)

Asgarpanah and Kazemivash (2012), Bamidele et al. (2011)

Osuntokun and Omolola (2019), Banjo et al. (2018),

Tsobou et al. (2015), MAriame et al.(2016), Arbonier (2019), Ariyo et al. (2020)

Katsayal and Danfodiyo (2002), Arbonier (2019), Bello et al. (2011)

Tamo et al. (2016), Tsobou et al. (2015), Erharuyil et al. (2014)

Afolayan et al. (2018), Kazhila (2016), Njayou et al. (2008)

Arbonier (2019), Yesufu et al. (2014), Kaboré et al. (2014)

Tsobou et al. (2015)

Singh et al. (2019), Musa et al. (2018)

Archer et al. (2019), Archer et al. (2019)

Yinyang et al. (2014), Noumedem et al. (2013), Ramya et al. (2011)

Kannan et al. (2012), Jaiswal (2012), Kuete and Efferth (2010),

Yemele et al. (2014)

Salih et al. (2018), Salih et al. (2017)

Cough, Fever

Myalgia 


\begin{tabular}{|c|c|c|c|c|c|}
\hline Trichilia emetica & Meliaceae & Bk, L & $\begin{array}{l}\text { Cough, Fever, } \\
\text { Myalgia }\end{array}$ & $\begin{array}{l}\text { Alk, Phen, Tan, } \\
\text { Terp }\end{array}$ & $\begin{array}{l}\text { Arbonier (2019), Kouitcheu et al. (2017), Diarra et al. } \\
\text { (2015), Šutovská et al. (2009) }\end{array}$ \\
\hline Vernonia amygdalina & Asteraceae & L & $\begin{array}{l}\text { Cough, Fever, } \\
\text { Myalgia }\end{array}$ & Terp & Fongnzossie et al. (2017), Yeep et al. (2010) \\
\hline Vernonia colorata & Asteraceae & $\mathrm{L}$ & $\begin{array}{l}\text { Cough, Fever, } \\
\text { Myalgia }\end{array}$ & Terp & Tsobou et al. (2015), Cioffi et al. (2014) \\
\hline Vitellaria paradoxa & Sapotaceae & $\mathrm{Bk}, \mathrm{Fr}$ & $\begin{array}{l}\text { Cough, Fever, } \\
\text { Myalgia }\end{array}$ & Terp & $\begin{array}{l}\text { Mbaveng et al. (2011), Maanikuu and Peker (2017), } \\
\text { Israel (2014), Fongnzossie et al. (2017) }\end{array}$ \\
\hline Vitex simplicifolia & Verbenaceae & $\mathrm{L}$ & $\begin{array}{l}\text { Cough, Fever, } \\
\text { Myalgia }\end{array}$ & $\begin{array}{l}\text { Alk, Phen, Tan, } \\
\text { Terp }\end{array}$ & $\begin{array}{l}\text { Arbonier (2019) Salim and Dikko (2016), Salim and } \\
\text { Imam (2016) }\end{array}$ \\
\hline Ximenia americana & Olacaceae & L, Fr & $\begin{array}{l}\text { Cough, Fever, } \\
\text { Myalgia }\end{array}$ & Phen, Tan, Terp & $\begin{array}{l}\text { Urso et al. (2013), Hunde Feyssa et al. (2012), Monte } \\
\text { et al. (2012) }\end{array}$ \\
\hline
\end{tabular}

** Alk= alkaloids, $\mathrm{Tan}=$ tannins, Terp= terpenoids, $\mathrm{Ph}=\mathrm{Phenolics}$ 


\subsection{State of knowledge on Cameroonian medicinal plants with confirmed anti- inflammatory, anti-viral and immunostimulant properties}

Evidence from researches conducted on SARS-COV and COVID-19 shows that the weakening of the immune system is one of the major contributing factors to the increased incidence of COVID complications like pneumonia and mortality in affected patients (Curbelo et al. 2017; Taghizadeh and Akbari, 2020; Prompetchara et al., 2020). These authors argued that improving the immune system response may be effective in reducing the incidence of pneumonia and reduction of inflammation may be effective in reducing the mortality rates due to pneumonia. From the literature data compiled, about 10 species have been documented for their beneficial effect in boosting the immune system. Among these species, 3 were also cited to treat at least 3 symptoms of COVID-19: Azadirachta indica and Momordica charantia and Vernonia amygdalina (table 4). Of the total of 52 species documented for their anti-inflamatory activity, there are also 11 cited as used to treat Covi-19 symptoms. These are: Acanthus montanus, Eleusine indica, Entandrophragma cylindricum, Eremomastax speciosa, Erythrophleum suaveolens, Jatropha curcas, Kalanchoe crenata, Picralima nitida, Senna alata, Solanum torvum, Spathodea campanulata Vernonia amygdalina, and Vitellaria paradoxa (table 4). A total of 14 species were cited for their antiviral properties on other virus-induced diseases, of which 3 are traditionally used to manage COVID-19 symptoms: Anickia chlorantha, Artemisia annua, Costus afer, Senna alata and Vernonia amygdalina (table 4). A total of 78 species have been documented as used to treat malaria. Overall, the leaves, barks and roots are the most used plant parts (figure 3). 


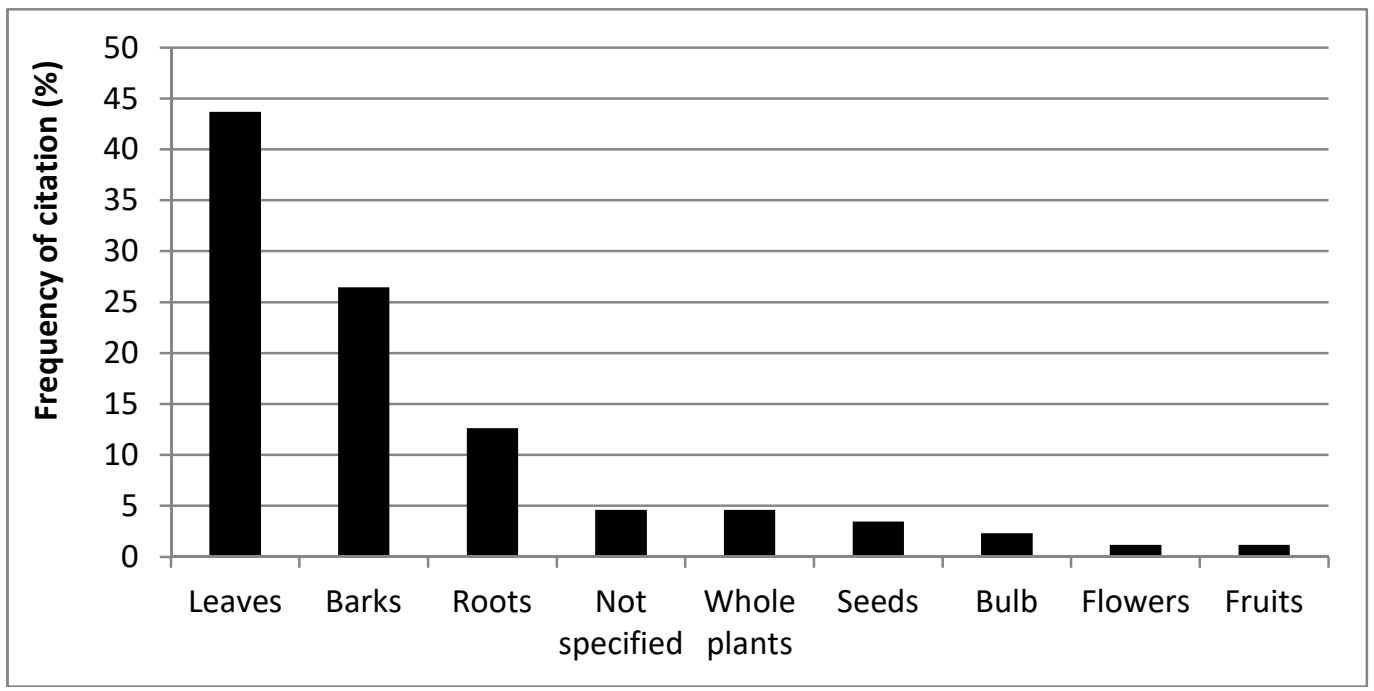

Figure 3. Frequency distribution of plant parts with imunomodulatory, antiinflammatory or antiviral properties

Overall, these species belongs to 53 different botanical families. The families with higher number of representatives are Caesalpiniaceae (10 species), Asteraceae (3 species), Cucurbitaceae and Apocynaceae (3 species), Euphorbiaceae, Lamiaceae, Meliaceae, Acanthaceae, Combretaceae, Euphorbiaceae, Meliaceae and Mimosaceae (2 species). 
Table 4. Recorded plants documented for their anti-inflammatory, anti-viral and/or immunostimulant properties

\begin{tabular}{|c|c|c|c|c|}
\hline Scientific name & Family & Part used & Existing pharmacological records & Reference \\
\hline Acacia polyacantha & Fabaceae & Leaves & Antimalaria & Bashige-Chiribagula et al. (2017) \\
\hline Acanthus montanus & Acanthaceae & $\mathrm{L}$ & Anti-inflammatory & Kuete and Efferth (2010) \\
\hline Adenocarpus mannii & Caesalpiniaceae & $\mathrm{L}$ & $\begin{array}{l}\text { Methanol extracts possess immunomodulatory } \\
\text { activity }\end{array}$ & Kuate (2015) \\
\hline $\begin{array}{l}\text { Aframomum citratum } \\
\text { Aframomum latifolium } \\
\text { Aframomum melegueta } \\
\text { Aframomum sceptrum } \\
\text { Aframomum zambesiacum } \\
\text { Ageratum conyzoides } \\
\text { Albizia adiantifolia } \\
\text { Albizia zygia }\end{array}$ & $\begin{array}{l}\text { Zingiberaceae } \\
\text { Zingiberaceae } \\
\text { Zingiberaceae } \\
\text { Zingiberaceae } \\
\text { Zingiberaceae } \\
\text { Asteraceae } \\
\text { Mimosaceae } \\
\text { Mimosaceae } \\
\end{array}$ & $\begin{array}{l}\text { Fruit } \\
\text { Fruit } \\
\text { Seeds } \\
\text { Fruit } \\
\text { Fruit } \\
\text { L } \\
\text { Leaves } \\
\text { L, Rt }\end{array}$ & $\begin{array}{l}\text { Antimalaria } \\
\text { Antimalaria } \\
\text { Antimalaria } \\
\text { Antimalaria } \\
\text { Antimalaria } \\
\text { Antimalaria } \\
\text { Antimalaria } \\
\text { Anti-inflammatory }\end{array}$ & $\begin{array}{l}\text { Tane et al. (2005) } \\
\text { Tane et al. (2005) } \\
\text { Tane et al. (2005) } \\
\text { Tane et al. (2005) } \\
\text { Tane et al. (2005) } \\
\text { Jiofack et al. (2008), Yinyang et al. } \\
(2014) \\
\text { Bashige-Chiribagula et al. (2017) } \\
\text { Asante-Kwatia et al. (2020) }\end{array}$ \\
\hline $\begin{array}{l}\text { Albizia zygia } \\
\text { Alchemilla kiwuensis }\end{array}$ & $\begin{array}{l}\text { Mimosaceae } \\
\text { Rosaceae }\end{array}$ & $\begin{array}{l}\text { Leaf } \\
\mathrm{Wp}\end{array}$ & $\begin{array}{l}\text { Antimalaria } \\
\text { Anti-inflammatory }\end{array}$ & $\begin{array}{l}\text { Titanji et al. (2008) } \\
\text { Kamtchueng et al. (2017) }\end{array}$ \\
\hline $\begin{array}{l}\text { Alchornea cordifolia } \\
\text { Allanblackia monticola }\end{array}$ & $\begin{array}{l}\text { Euphorbiaceae } \\
\text { Clusiaceae }\end{array}$ & $\begin{array}{l}\mathrm{L} \\
\mathrm{Bk}\end{array}$ & $\begin{array}{l}\text { Antimalaria } \\
\text { Anti-inflammatory }\end{array}$ & $\begin{array}{l}\text { Ngoupayo et al. (2015) } \\
\text { Kuete and Efferth (2010) }\end{array}$ \\
\hline $\begin{array}{l}\text { Allanblackia monticola } \\
\text { Allium sativum }\end{array}$ & $\begin{array}{l}\text { Clusiaceae } \\
\text { Liliaceae }\end{array}$ & $\begin{array}{l}\text { Stem bark } \\
\mathrm{Bu}\end{array}$ & $\begin{array}{l}\text { Antimalaria } \\
\text { Anti-inflammatory, antioxidant, bronchitis, chronic } \\
\text { fever }\end{array}$ & $\begin{array}{l}\text { Titanji et al. (2008) } \\
\text { Khodadadi (2015) }\end{array}$ \\
\hline $\begin{array}{l}\text { Allium sativum } \\
\text { Alstonia boonei } \\
\text { Anisophyllea pomisofera } \\
\text { Annickia chlorantha }\end{array}$ & $\begin{array}{l}\text { Liliaceae } \\
\text { Sapotaceae } \\
\text { Rhizophoraceae } \\
\text { Anonaceae }\end{array}$ & $\begin{array}{l}\text { Bulb } \\
\text { Bk, Lx, L } \\
\text { Leaves } \\
\text { Bk }\end{array}$ & $\begin{array}{l}\text { Antimalaria } \\
\text { Antimalaria } \\
\text { Antimalaria } \\
\text { Antiviral (Hepatitis A,B; C and D) }\end{array}$ & $\begin{array}{l}\text { Khodadadi (2015) } \\
\text { Jiofack et al. (2008 \& 2009), Dibong et } \\
\text { al. (2015) } \\
\text { Bashige-Chiribagula et al. (2017) } \\
\text { Ngono Ngane et al. (2011) }\end{array}$ \\
\hline $\begin{array}{l}\text { Annona muricata } \\
\text { Anogeissus leiocarpus } \\
\text { Anonidium mannii } \\
\end{array}$ & $\begin{array}{l}\text { Annonaceae } \\
\text { Combretaceae } \\
\text { Anonaceae } \\
\end{array}$ & $\begin{array}{l}\text { L, Fr, Se, Pulp } \\
\text { Leaves } \\
\text { Bk }\end{array}$ & $\begin{array}{l}\text { Antimalaria } \\
\text { Antimalaria } \\
\text { Antiinflammatory }\end{array}$ & $\begin{array}{l}\text { Yinyang et al. ( 2014), Tsobou et al. } \\
(2015) \\
\text { Ahmad (2014) } \\
\text { Mokale Kognou et al. (2020) }\end{array}$ \\
\hline Anopyxis klaineana & Rhizophoraceae & $\mathrm{Bk}$ & Anti-inflammatory & Asante-Kwatia et al. (2020) \\
\hline Anthocleista djalonensis & Loganiaceae & & Antimalaria & Bassey et al. (2009) \\
\hline
\end{tabular}




\begin{tabular}{|c|c|c|c|c|}
\hline $\begin{array}{l}\text { Antidesma laciniatum } \\
\text { Araliopsis tabuensis } \\
\text { Artemisia annua }\end{array}$ & $\begin{array}{l}\text { Euphorbiaceae } \\
\text { Rutaceae } \\
\text { Asteraceae }\end{array}$ & $\begin{array}{l}\text { Leaf } \\
\text { Stem bark } \\
\text { L }\end{array}$ & $\begin{array}{l}\text { Antimalaria } \\
\text { Antimalaria } \\
\text { Anti-HIV activity }\end{array}$ & $\begin{array}{l}\text { Titanji et al. (2008) } \\
\text { Titanji et al. (2008) } \\
\text { Noumi and Manga (2011) }\end{array}$ \\
\hline Asystasia intrusa & Acanthaceae & $\mathrm{L}$ & Immunomodulatory activity of methanol extracts & Kuate (2015) \\
\hline Azadirachta indica & Meliaceae & $\mathrm{L}, \mathrm{Fl}, \mathrm{Bk}, \mathrm{Se}$ & $\begin{array}{l}\text { Anti-inflammatory, antioxidant, immunomodulatory, } \\
\text { antimalaria }\end{array}$ & $\begin{array}{l}\text { Agbor et al. (2007), Rahmani et al. } \\
(2018), \text { Bashige-Chiribagula et al. } \\
(2017)\end{array}$ \\
\hline Bersama engleriana & Melianthaceae & $\mathrm{L}, \mathrm{Bk}, \mathrm{Rt}$ & $\begin{array}{l}\text { Methanol extracts from the Laves, bark and roots } \\
\text { inhibited at } 80 \% \text { the activity of the Human Immuno- } \\
\text { deficiency Virus (HIV) enzyme }\end{array}$ & Mbaveng et al. (2011) \\
\hline $\begin{array}{l}\text { Bersama engleriana } \\
\text { Bidens pilosa } \\
\text { Bobgunia madagascariensis } \\
\text { Bridelia scleroneura } \\
\end{array}$ & $\begin{array}{l}\text { Meliantaceae } \\
\text { Asteraceae } \\
\text { Fabaceae } \\
\text { Euphorbiaceae } \\
\end{array}$ & $\begin{array}{l}\text { Leaf } \\
\text { Stem bark, } \\
\text { Bk, Rt }\end{array}$ & $\begin{array}{l}\text { Antimalaria } \\
\text { Antimalaria } \\
\text { Antimalaria } \\
\text { Anti-inflammatory } \\
\end{array}$ & $\begin{array}{l}\text { Titanji et al. (2008) } \\
\text { Titanji et al. (2008) } \\
\text { Bashige-Chiribagula et al. (2017) } \\
\text { Kuete and Efferth (2010) } \\
\end{array}$ \\
\hline $\begin{array}{l}\text { Cajanus cajan } \\
\text { Calotropis procera }\end{array}$ & $\begin{array}{l}\text { Fabaceae } \\
\text { Apocynaceae }\end{array}$ & $\begin{array}{l}\text { Roots, leaf } \\
\text { L }\end{array}$ & $\begin{array}{l}\text { Antimalaria } \\
\text { Anti-inflammatory }\end{array}$ & $\begin{array}{l}\text { Titanji et al. (2008) } \\
\text { Asante-Kwatia et al. (2020) }\end{array}$ \\
\hline Capparis erythrocarpos & Capparidaceae & $\mathrm{L}$ & Anti-inflammatory & Asante-Kwatia et al. (2020) \\
\hline Carica papaya & Caricaceae & $\mathrm{L}, \mathrm{Fr}$ & Anti-inflammatory, antimalaria & $\begin{array}{l}\text { Sagnia et al. (2014), Sebua and Maroyi } \\
(2013)\end{array}$ \\
\hline Cassia alata & Caesalpiniaceae & $\mathrm{L}$ & Anti-inflammatory & Sagnia et al. (2014) \\
\hline $\begin{array}{l}\text { Cassia occidentalis } \\
\text { Cassia sieberiana }\end{array}$ & $\begin{array}{l}\text { Fabaceae } \\
\text { Caesalpiniaceae }\end{array}$ & $\begin{array}{l}\text { Leaves } \\
\text { Rt }\end{array}$ & $\begin{array}{l}\text { Antimalaria } \\
\text { Anti-inflammatory }\end{array}$ & $\begin{array}{l}\text { Bashige-Chiribagula et al. (2017) } \\
\text { Asante-Kwatia et al. (2020) }\end{array}$ \\
\hline Caucalis melanantha & Apiaceae & $\mathrm{L}$ & Immunomodulatory activity of methanol extracts & (Kuate, 2015) \\
\hline Ceiba pentandra & Bombacaceae & $\mathrm{Bk}$ & Anti-inflammatory & $\begin{array}{l}\text { Agbor et al. (2007), Elion Itou et al. } \\
\text { (2014) }\end{array}$ \\
\hline Clematis chinensis & Ranunculaceae & $\mathrm{L}$ & Immunomodulatory activity of methanol extracts & Kuate (2015) \\
\hline $\begin{array}{l}\text { Cleone rutidosperma } \\
\text { Combretum molle }\end{array}$ & $\begin{array}{l}\text { Capparidaceae } \\
\text { Combretaceae }\end{array}$ & $\begin{array}{l}\text { Leaf } \\
\text { Bk }\end{array}$ & $\begin{array}{l}\text { Antimalaria } \\
\text { Anti-inflammatory }\end{array}$ & $\begin{array}{l}\text { Titanji et al. (2008) } \\
\text { Kuete and Efferth (2010) }\end{array}$ \\
\hline Commelina diffusa & Commelinaceae & $\mathrm{L}$ & Anti-inflammatory & Asante-Kwatia et al. (2020) \\
\hline Costus afer & Costaceae & $\mathrm{St}$ & $\begin{array}{l}\text { Antiviral (chicken pox, influenza, measles and } \\
\text { genital herpes) }\end{array}$ & Ngono Ngane et al. (2011) \\
\hline Cucurbita maxima & Cucurbitaceae & $\mathrm{L}$ & Anti-HIV activity & Noumi and Manga (2011) \\
\hline Cucurbita pepo & Cucurbitaceae & $\mathrm{L}, \mathrm{Rt}$ & Inhibits HIV-1 reverse transcriptase & Noumi and Manga (2011) \\
\hline Cylicodiscus gabinensis & Mimosaceae & $\mathrm{Bk}$ & Anti-oxidant, anti-malarial & (Agbor et al.. 2007 ; Mounguengui et \\
\hline
\end{tabular}




\begin{tabular}{|c|c|c|c|c|}
\hline & & & & al., 2016) \\
\hline $\begin{array}{l}\text { Cylicodiscus gabunensis } \\
\text { Cymbopogon citratus } \\
\text { Daucus carota }\end{array}$ & $\begin{array}{l}\text { Mimosaceae } \\
\text { Poaceae } \\
\text { APiaceae }\end{array}$ & $\begin{array}{l}\text { Leaf, stem bark } \\
\text { L } \\
\text { L }\end{array}$ & $\begin{array}{l}\text { Antimalaria } \\
\text { Antimalaria } \\
\text { Inhibits HSV-1 replication }\end{array}$ & $\begin{array}{l}\text { Titanji et al. (2008) } \\
\text { Etame et al. (2018), Yemele et al. } \\
\text { (2014), Yinyang et al. (2014) } \\
\text { Noumi and Manga (2011) }\end{array}$ \\
\hline Dichaetanthera africana & $\begin{array}{l}\text { Melastomatacea } \\
\text { e }\end{array}$ & $\mathrm{Bk}$ & Anti-inflammatory & $\begin{array}{l}\text { Oguntibeju (2018), Mokale Kognou et } \\
\text { al. (2017) }\end{array}$ \\
\hline Eleusine indica & Poaceae & $\mathrm{L}$ & Anti-inflammatory & Sagnia et al. (2014) \\
\hline $\begin{array}{l}\text { Enantia clorantha } \\
\text { Entada abyssinica } \\
\text { Entandrophragma } \\
\text { cylindricum } \\
\end{array}$ & $\begin{array}{l}\text { Annonaceae } \\
\text { Mimosaceae } \\
\text { Meliaceae }\end{array}$ & $\begin{array}{l}\text { Stem bark } \\
\text { Leaves } \\
\text { Bk }\end{array}$ & $\begin{array}{l}\text { Antimalaria } \\
\text { Antimalaria } \\
\text { Anti-inflammatory }\end{array}$ & $\begin{array}{l}\text { Titanji et al. (2008) } \\
\text { Bashige-Chiribagula et al. (2017) } \\
\text { Fogue Kouam et al. (2012)? Mokale } \\
\text { Kognou et al. (2020) }\end{array}$ \\
\hline $\begin{array}{l}\text { Enthadrophragma angolense } \\
\text { Eremomastax speciosa }\end{array}$ & $\begin{array}{l}\text { Meliaceae } \\
\text { Acanthaceae }\end{array}$ & $\begin{array}{l}\text { Stem bark, leaf } \\
\mathrm{L}\end{array}$ & $\begin{array}{l}\text { Antimalaria } \\
\text { Anti-inflammatory }\end{array}$ & $\begin{array}{l}\text { Titanji et al. (2008) } \\
\text { Sagnia et al. (2014) }\end{array}$ \\
\hline Erythrina addisoniae & Caesalpiniaceae & $\mathrm{Bk}$ & Anti-inflammatory & Kuete and Efferth (2010) \\
\hline Erythrina mildbraedii & Caesalpiniaceae & $\mathrm{Rt}$ & Anti-inflammatory & Kuete and Efferth (2010) \\
\hline Erythrina sigmoidea & Caesalpiniaceae & $\mathrm{Rt}$ & Anti-inflammatory & Kuete and Efferth (2010) \\
\hline Erythrophleum ivorense & Caesalpiniaceae & Not precised & Anti-inflammatory & Asante-Kwatia et al. (2020) \\
\hline ErythrophLum suaveoLns & Caesalpiniaceae & $\mathrm{Bk}$ & Anti-inflammatory & Kuete and Efferth (2010) \\
\hline $\begin{array}{l}\text { Euphorbia hirta } \\
\text { Ficus exasperata }\end{array}$ & $\begin{array}{l}\text { Euphorbiaceae } \\
\text { Moraceae }\end{array}$ & $\begin{array}{l}\text { Wp } \\
\mathrm{L}\end{array}$ & $\begin{array}{l}\text { Antimalaria } \\
\text { Anti-inflammatory }\end{array}$ & $\begin{array}{l}\text { Tamo et al. (2016), } \\
\text { Asante-Kwatia et al. (2020) }\end{array}$ \\
\hline $\begin{array}{l}\text { Ficus exasperata } \\
\text { Ficus thonningii } \\
\text { Glossocalyx brevipes - } \\
\text { Glyphaea brevis }\end{array}$ & \begin{tabular}{|l|} 
Moraceae \\
Moraceae \\
Monimiaceae \\
Tilliaceae \\
\end{tabular} & $\begin{array}{l}\text { Leaf } \\
\text { Leaf } \\
\text { Leaf } \\
\text { L, Bk } \\
\end{array}$ & $\begin{array}{l}\text { Antimalaria } \\
\text { Antimalaria } \\
\text { Antimalaria } \\
\text { Anti-inflammatory } \\
\end{array}$ & $\begin{array}{l}\text { Titanji et al. (2008) } \\
\text { Titanji et al. (2008) } \\
\text { Titanji et al. (2008) } \\
\text { Asante-Kwatia et al. (2020) }\end{array}$ \\
\hline $\begin{array}{l}\text { Gossypium spp. } \\
\text { Harungana madagascariensis } \\
\text { Harungana madagascariensis } \\
\text { Hexalobus crispiflorus } \\
\text { Hilleria latifolia }\end{array}$ & $\begin{array}{l}\text { Malvaceae } \\
\text { Clusiaceae } \\
\text { Hypericaceae } \\
\text { Annonaceae } \\
\text { Phytolacaceae }\end{array}$ & $\begin{array}{l}\text { Cottonseed } \\
\text { Bark } \\
\text { Bk } \\
\text { Leaf, seed } \\
\text { Wp } \\
\end{array}$ & $\begin{array}{l}\text { Antimalaria } \\
\text { ANtimalaria } \\
\text { Antimalaria } \\
\text { Antimalaria } \\
\text { Anti-inflammatory }\end{array}$ & $\begin{array}{l}\text { Titanji et al. (2008) } \\
\text { Weniger et al. (2008) } \\
\text { Ndam et al. (2014) } \\
\text { Titanji et al. (2008) } \\
\text { Asante-Kwatia et al. (2020) }\end{array}$ \\
\hline $\begin{array}{l}\text { Holarrhena floribunda } \\
\text { Jatropha curcas }\end{array}$ & $\begin{array}{l}\text { Apocynaceae } \\
\text { Euphorbiaceae }\end{array}$ & $\begin{array}{l}\mathrm{Bk}, \mathrm{L} \\
\mathrm{Rt}\end{array}$ & $\begin{array}{l}\text { Antimalaria } \\
\text { Anti-inflammatory }\end{array}$ & $\begin{array}{l}\text { Yinyang et al. (2014) } \\
\text { Asante-Kwatia et al. (2020) }\end{array}$ \\
\hline Kalanchoe crenata & Crassulacées & Not specified & Anti-inflammatory & Kuete and Efferth (2010) \\
\hline Khaya senegalensis & Meliaceae & $\mathrm{L}, \mathrm{Fr}$ & Antimalaria & Arbonier (2019), Makut et al. (2008) \\
\hline
\end{tabular}




\begin{tabular}{|c|c|c|c|c|}
\hline Lactuca capensis & Asteraceae & Not specified & $\begin{array}{l}\text { Treatment of HIV/AIDS and related opportunistic } \\
\text { infections }\end{array}$ & Tchuenguem et al. (2017) \\
\hline $\begin{array}{l}\text { Landolfia kirkii } \\
\text { Mallotus oppositofolius } \\
\text { Mangifera indica } \\
\text { Milletia griffoniana }\end{array}$ & $\begin{array}{l}\text { Apocynaceae } \\
\text { Euphorbiaceae } \\
\text { Anacardiaceae } \\
\text { Caesalpiniaceae }\end{array}$ & $\begin{array}{l}\text { Leaves, Stem } \\
\text { bark } \\
\text { Leaf } \\
\text { Bk } \\
\text { L } \\
\end{array}$ & $\begin{array}{l}\text { Antimalaria } \\
\text { Antimalaria } \\
\text { Antimalaria } \\
\text { Anti-inflammatory }\end{array}$ & $\begin{array}{l}\text { Bashige-Chiribagula et al. (2017) } \\
\text { Titanji et al. (2008) } \\
\text { Yemele et al. (2014), Yinyang et al. } \\
(2014) \\
\text { Kuete and Efferth (2010) }\end{array}$ \\
\hline Milletia versicolor & Caesalpiniaceae & $\mathrm{L}$ & Anti-inflammatory & Kuete and Efferth (2010) \\
\hline $\begin{array}{l}\text { Millettia griffoniana } \\
\text { Momordica charantia }\end{array}$ & $\begin{array}{l}\text { Leguminoceae- } \\
\text { Papilionoideae } \\
\text { Cucurbitaceae }\end{array}$ & $\begin{array}{l}\text { Leaf, stem bark } \\
\text { L }\end{array}$ & $\begin{array}{l}\text { Antimalaria } \\
\text { Immunomodulatory activity, antiviral (Chicken-pox } \\
\text { Measles Genital herpes Shingles) }\end{array}$ & $\begin{array}{l}\text { Titanji et al. (2008) } \\
\text { Mahamat et al. (2020), Ngono Ngane et } \\
\text { al. (2011) }\end{array}$ \\
\hline $\begin{array}{l}\text { Momordica charantia } \\
\text { Moringa oleifera }\end{array}$ & $\begin{array}{l}\text { Cucurbitaceae } \\
\text { Moringaceae }\end{array}$ & $\begin{array}{l}\mathrm{L} \\
\mathrm{L}, \mathrm{Se}\end{array}$ & $\begin{array}{l}\text { Antimalaria } \\
\text { Boost appetite and immunity, anti-HIV activity }\end{array}$ & $\begin{array}{l}\text { Jiofack et al. (2009), Mozaniel et al. } \\
\text { (2018) } \\
\text { Noumi and Manga (2011) }\end{array}$ \\
\hline $\begin{array}{l}\text { Musa paradisiaca } \\
\text { Neoboutonia velutina } \\
\text { Newbouldia laevis } \\
\end{array}$ & $\begin{array}{l}\text { Moraceae } \\
\text { Euphorbiaceae } \\
\text { Bigoniaceae } \\
\end{array}$ & $\begin{array}{l}\text { Leaf } \\
\text { Leaf, stem bark } \\
\text { L }\end{array}$ & $\begin{array}{l}\text { Antimalaria } \\
\text { Antimalaria } \\
\text { Anti-inflammatory } \\
\end{array}$ & $\begin{array}{l}\text { Titanji et al. (2008) } \\
\text { Titanji et al. (2008) } \\
\text { Asante-Kwatia et al. (2020) } \\
\end{array}$ \\
\hline Occimum gratissimum & Lamiaceae & $\mathrm{L}$ & Immunomodulatory activity of methanol extracts & Kuate (2015) \\
\hline Ocimum basilicum & Lamiaceae & $\mathrm{L}$ & Inhibits HIV-1 reverse transcriptase & Noumi and Manga (2011) \\
\hline $\begin{array}{l}\text { Ocimum gratissimum } \\
\text { Odyendyea gabonensis } \\
\text { Pachypodanthium confine } \\
\text { Palisota hirsuta } \\
\end{array}$ & \begin{tabular}{|l|} 
Lamiaceae \\
Simaroubaceae \\
Annonaceae \\
Commelinaceae \\
\end{tabular} & $\begin{array}{l}\text { Leaves } \\
\text { Leaf, stem bark } \\
\text { Leaf } \\
\text { L } \\
\end{array}$ & $\begin{array}{l}\text { Antimalaria } \\
\text { Antimalaria } \\
\text { Anti-inflammatory } \\
\end{array}$ & $\begin{array}{l}\text { Bashige-Chiribagula et al. (2017) } \\
\text { Titanji et al. (2008) } \\
\text { Titanji et al. (2008) } \\
\text { Asante-Kwatia et al. (2020) } \\
\end{array}$ \\
\hline Panda oleosa & Pandaceae & Bk & $\begin{array}{l}\text { Used in traditional medicine in Kisangani city to } \\
\text { treat various diseases including diabetes and } \\
\text { HIV/AIDs }\end{array}$ & (Muhoya et al., 2017) \\
\hline $\begin{array}{l}\text { Peniantus longifolius } \\
\text { Pentadiplandra brazzeana } \\
\text { Peperomia vulcanica } \\
\text { Phyllanthus muellerianus }\end{array}$ & $\begin{array}{l}\text { Menispermaceae } \\
\text { Pentadiplandrace } \\
\text { ae } \\
\text { Piperaceae } \\
\text { Euphorbiaceae }\end{array}$ & $\begin{array}{l}\text { Stem bark } \\
\text { Leaf, stem bark } \\
\text { Leaf } \\
\text { Wp }\end{array}$ & $\begin{array}{l}\text { Antimalaria } \\
\text { Antimalaria } \\
\text { Antimalaria } \\
\text { Anti-inflammatory }\end{array}$ & $\begin{array}{l}\text { Titanji et al. (2008) } \\
\text { Titanji et al. (2008) } \\
\text { Titanji et al. (2008) } \\
\text { Asante-Kwatia et al. (2020), } \\
\text { Ogunwande et al. (2019) }\end{array}$ \\
\hline Phyllantus muellerianus & Euphorbiaceae & Leaf, stem bark & Antimalaria & Titanji et al. (2008) \\
\hline
\end{tabular}




\begin{tabular}{|c|c|c|c|c|}
\hline Picralima nitida & Apocynaceae & $\mathrm{Se}$ & Anti-inflammatory & Asante-Kwatia et al. (2020) \\
\hline Picralima nitida & Apocynaceae & Fr, Rt & Antimalaria & Tamo et al. (2016), Tsobou et al. (2015) \\
\hline Piper nigrum & Piperaceae & Seed & Antimalaria & Titanji et al. (2008) \\
\hline Piper unbellatum. & Piperaceae & Leaf & Antimalaria & Titanji et al. (2008) \\
\hline Polyscias fulva & Araliaceae & $\mathrm{L}$ & Anti-inflammatory & Sagnia et al. (2014) \\
\hline Prunus africana & Rosaceae & $\mathrm{Bk}$ & & (Agbor et al., 2007) \\
\hline Pseudocedrela kotschyi & Meliaceae & $\mathrm{Bk}$ & Extracts stimulate monocyte proliferation response & Oumar et al. (2017) \\
\hline Psidium guayava & Myrtaceae & $\mathrm{L}$ & $\begin{array}{l}\text { Antibacterial, anti-malarial, anti-diarrhoeal, anti- } \\
\text { inflammatory, antioxidant activity? antimalaria }\end{array}$ & $\begin{array}{l}\text { Agbor et al. (2007, Titanji et al. (2008), } \\
\text { Kaur et al (2018) }\end{array}$ \\
\hline Pteleopsis hylodendrom & Combretaceae & $\mathrm{Bk}$ & $\begin{array}{l}\text { Antiviral (chicken pox, influenza, measles and } \\
\text { genital herpes) }\end{array}$ & Ngono Ngane et al. (2011) \\
\hline $\begin{array}{l}\text { Pycnanthus angolensis } \\
\text { Raphanus sativus }\end{array}$ & $\begin{array}{l}\text { Myrtaceae } \\
\text { Brassicaceae }\end{array}$ & $\begin{array}{l}\text { Leaf, stem bark } \\
\text { L, Bk, Rt }\end{array}$ & $\begin{array}{l}\text { Antimalaria } \\
\text { Antiviral activity } \\
\end{array}$ & $\begin{array}{l}\text { Titanji et al. (2008) } \\
\text { Noumi and Manga (2011) } \\
\end{array}$ \\
\hline Rauvolfia macrophylla & Apocynaceae & Stem bark & Antimalaria & Weniger et al. (2008) \\
\hline Rauvolfia vomitoria & Apocynaceae & Stem bark & Antimalaria & Titanji et al. (2008) \\
\hline Reneilmia cincinnata & Zingiberaceae & Fruit & Antimalaria & Titanji et al. (2008) \\
\hline $\begin{array}{l}\text { Schumanniophyton } \\
\text { magnificum }\end{array}$ & Rubiaceae & Stem bark & Antimalaria & Titanii et al (2008) \\
\hline $\begin{array}{l}\text { magnijlcum } \\
\text { Sclerocarya birrea }\end{array}$ & Anacardiaceae & $\begin{array}{l}\text { stem bark } \\
\text { Bk }\end{array}$ & $\begin{array}{l}\text { Antimalaria } \\
\text { Anti-inflammatory }\end{array}$ & $\begin{array}{l}\text { 11tanj1 et al. (2008) } \\
\text { Kuete and Efferth (2010) }\end{array}$ \\
\hline $\begin{array}{l}\text { Scoparia dulcis } \\
\text { Senna alata }\end{array}$ & $\begin{array}{l}\text { Scrophulariaceae } \\
\text { Caesalpiniaceae }\end{array}$ & $\begin{array}{l}\text { Whole plant } \\
\text { L }\end{array}$ & $\begin{array}{l}\text { Antimalaria } \\
\text { Inhibits HIV-1 reverse transcriptase }\end{array}$ & $\begin{array}{l}\text { Titanji et al. (2008) } \\
\text { Noumi and Manga (2011) }\end{array}$ \\
\hline Solanum torvum & Solanaceae & $\mathrm{L}$ & Anti-inflammatory & Kuete and Efferth (2010) \\
\hline Spathodea campanulata & Bignoniaceae & $\mathrm{L}, \mathrm{Bk}$ & $\begin{array}{l}\text { Anti-inflammatory, antioxidant } \\
\text { Antiviral (Chicken-pox Genital herpes) }\end{array}$ & $\begin{array}{l}\text { Pone (2017), Etame et al. (2018), Ngono } \\
\text { Ngane et al. (2011) }\end{array}$ \\
\hline $\begin{array}{l}\text { Stachytapheta cayenensis } \\
\text { Stereospermum }\end{array}$ & Verbenaceae & Leaf & Antimalaria & Titanji et al. (2008) \\
\hline acuminatissimum & Bignoniaceae & Bark & Antimalaria & Weniger et al. (2008) \\
\hline Stereospermum zenkeri & Bignoniaceae & Bark & Antimalaria & Weniger et al. (2008) \\
\hline Strychnos icaja & Loganiaceae (?) & Root & Antimalaria & Titanji et al. (2008) \\
\hline Symphonia globulifera & Clusiaceae & Bark & Antimalaria & Weniger et al. (2008) \\
\hline Synedrella nodiflora & & Wp & Anti-inflammatory & Asante-Kwatia et al. (2020) \\
\hline $\begin{array}{l}\text { Tapinanthus globiferus } \\
\text { (harvested from Persea } \\
\text { americana) }\end{array}$ & Loranthaceae & $\mathrm{L}$ & $\begin{array}{l}\text { Anti-inflammatory, immunomodulatory and } \\
\text { antioxidant properties }\end{array}$ & Gounoue et al. (2019) \\
\hline
\end{tabular}




\begin{tabular}{|c|c|c|c|c|}
\hline $\begin{array}{l}\text { Thomandersia hensii } \\
\text { Trichilia emetica } \\
\text { Trichilia monadelpha }\end{array}$ & $\begin{array}{l}\text { Acanthaceae } \\
\text { Meliaceae } \\
\text { Meliaceae }\end{array}$ & $\begin{array}{l}\text { Leaves, stem } \\
\text { bark } \\
\text { Bark } \\
\text { Bk } \\
\end{array}$ & $\begin{array}{l}\text { Antimalaria } \\
\text { Antimalaria } \\
\text { Anti-inflammatory }\end{array}$ & $\begin{array}{l}\text { Titanji et al. (2008) } \\
\text { Diarra et al. (2015) } \\
\text { Asante-Kwatia et al. (2020) }\end{array}$ \\
\hline $\begin{array}{l}\text { Turreanthus africanus } \\
\text { Uapaca guineensis }\end{array}$ & $\begin{array}{l}\text { Meliaceae } \\
\text { Euphorbiaceae }\end{array}$ & \begin{tabular}{|l|} 
seed \\
Not specified \\
\end{tabular} & $\begin{array}{l}\text { Antimalaria } \\
\text { Anti-inflammatory }\end{array}$ & $\begin{array}{l}\text { Titanji et al. (2008) } \\
\text { Kuete and Efferth (2010) }\end{array}$ \\
\hline Vernonia amygdalina & Asteraceae & $\mathrm{L}$ & Anti-inflammatory & Asante-Kwatia et al. (2020) \\
\hline Vernonia amygdalina & Asteraceae & $\mathrm{L}, \mathrm{Rt}$ & Anti-HIV activity & Noumi and Manga (2011) \\
\hline Vitellaria paradoxa & Sapotaceae & $\mathrm{Bk}$ & Anti-inflammatory & Foyet et al. (2015) \\
\hline Vitex thyrsiflora & & $\mathrm{Bk}$ & Anti-inflammatory & Mokale Kognou et al. (2020) \\
\hline Voacanga africana & Apocynaceae & $\mathrm{Bk}$ & Antioxidant & Adu et al. (2015), Agbor et al. (2007) \\
\hline Xylopia aethiopica & Annonaceae & $\mathrm{Fr}$ & Anti-inflammatory & Asante-Kwatia et al. (2020) \\
\hline $\begin{array}{l}\text { Xylopia parviflora, } \\
\text { Xylopia phloiodora, } \\
\text { Xymolox monosperma } \\
\text { Zanthoxylum heitzii }\end{array}$ & $\begin{array}{l}\text { Annonaceae } \\
\text { Annonaceae } \\
\text { Annonaceae } \\
\text { Rutaceae }\end{array}$ & $\begin{array}{l}\text { Seed } \\
\text { Seed } \\
\text { Leaf, stem bark } \\
\text { Bk }\end{array}$ & $\begin{array}{l}\text { Antimalaria } \\
\text { Antimalaria } \\
\text { Antimalaria } \\
\text { Antioxidant, antimalarial, antiinfmalatory, } \\
\text { immunorestorative }\end{array}$ & $\begin{array}{l}\text { Titanji et al. (2008) } \\
\text { Titanji et al. (2008) } \\
\text { Titanji et al. (2008) } \\
\text { Agbor et al. (2007), Sadeer et al. (2019), } \\
\text { Mokondjimobe et al. (2012) }\end{array}$ \\
\hline $\begin{array}{l}\text { Zingiber officinale } \\
\text { Ziziphus abyssinica }\end{array}$ & $\begin{array}{l}\text { Zingiberaceae } \\
\text { Rhamnaceae }\end{array}$ & $\begin{array}{l}\text { L, Rt } \\
\text { Rt }\end{array}$ & $\begin{array}{l}\text { Antimalaria, anti-HIV-1 activity } \\
\text { Anti-inflammatory }\end{array}$ & $\begin{array}{l}\text { Titanji et al. (2008), Noumi and Manga } \\
(2011) \\
\text { Asante-Kwatia et al. (2020) }\end{array}$ \\
\hline
\end{tabular}

* $\mathrm{L}=$ leave, $\mathrm{Bk}=$ bark, $\mathrm{St}=\mathrm{Stem}, \mathrm{Rt}=$ roots, $\mathrm{Fr}=$ fruit, $\mathrm{Se}=$ seed, $\mathrm{Fl}=$ flower, $\mathrm{Tbk}=$ root bark, $\quad \mathrm{Wp}=$ whole $\mathrm{plant}, \mathrm{Lx}=\mathrm{latex}$ 


\subsection{Summary and implication for the fight against COVID-19}

From this review, it appears that 230 Cameroonian medicinal plant species that are promising source of ingredients for the fight against the 2019 novel corona virus. Among these species, about 32 contain secondary metabolites that have already been confirmed as anti-COVID 19 molecules. These are Abelmoschus esculentus, Acacia Senegal, Allium sativum, Bryophyllum pinnatum, Camellia sinensis, Capsicum annuum, Cissus quadrangularis, Citrus limon, Citrus sinensis, Citrus spp, Cola acuminate, Cola anomala, Cola nitida, Combretum glutinosum, Curcuma longa, Echinops giganteus, Khaya grandifoliola, Kigelia Africana, Laportea aestuans, Morinda morindoides, Ochthocosmus africanus, Parkia biglobosa, Phyllanthus spp, Rauwolfia sp., Senna alata, Solanum melongena, Solanum torvum, Tephrosia preussii, Terminalia catappa, Terminalia ivorensis, Zanthoxyllum heitzii and Zingiber officinale.

Of the 230 species recorded, 102 are already documented for their traditional use to manage at least 3 common symptoms of COVID-19. The PCA analysis separated 4 groups of medicinal plant species with axis 1 and 2 explaining $65.7 \%$ of the variability within the sample (figure 4).

The first group consists of plants treating at least three symptoms of COVID 19, containing key phytochemicals reported as being of interest for COVID management (alkaloids, phenolics, tannins and terpenoids) and having antimalaria properties. Representative species include Abelmoschus esculentus, Artemisia annua, Capsicum annun, Curcuma longa, Eucalyptus camaldulensis, Eremomastax speciosa, Kalenchoe crenata, Lippia multiflora, Morinda lucida, Senna alata, Solanum torvum, etc.

The second group consists of lead promising species like Azadirachta indica, Harungana madagascariensis, Mangifera indica, Momordica charantia, Picralima nitida, Trichilia 
emetica. This consists of plants used to treat COVID-19 symptoms which, at the same time are soure of the key phytochemicals and also have relevant pharmacological activities (antiviral, anti-inflammatory, immunostimulant, or containing secondary metabolites with confirmed anti-SARSCOV2 activity. Even when used alone, they can be evaluated and developed as potential remedy, while the other species may be used in association to each other for their complementary effects.

The third group consists of potential anti-malaria, agents based on the species Allium sativum, Psidium guajava, Phyllanthus muellerianus, Occimum gratissimum, Stereospermom acuminatissimum, etc.

The fourth group consists of immunostimulants, antiinflamatory, antiviral agents and plants wontaining some secondary metabolites with confirmed antiCOVID19 properties, with representative species like Moringa oleifera, Panda oleosa, Tapinanthus globuliferus, Zanthoxyllum heitzii, and Vernonia amygdalina..

Overall, the recorded medicinal plant species offers an array of possibility of using individual species or combination of species for their complementary effects, based on the clinical symptoms showed by the patients and the therapeutic objective to be achieved. 


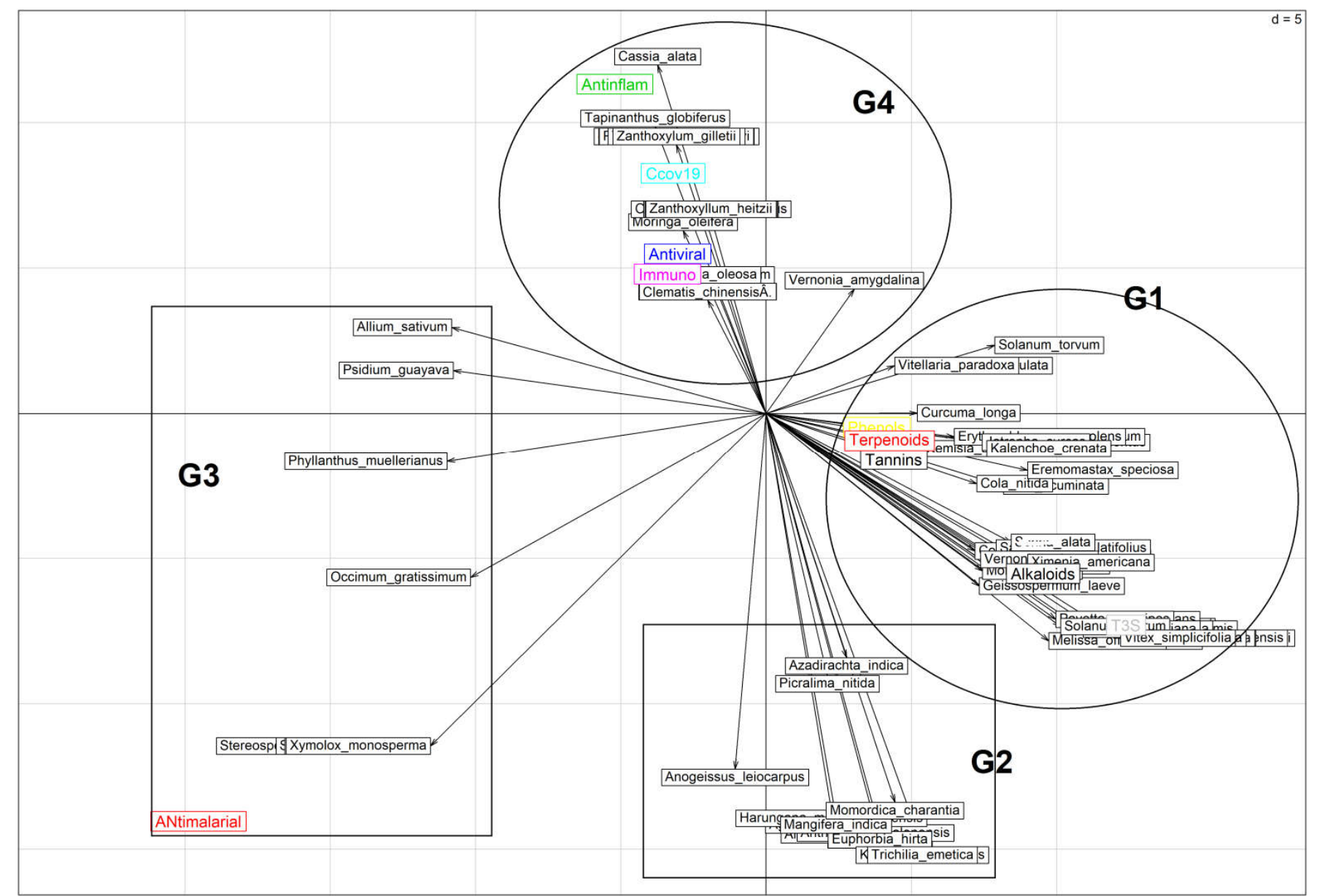

Figure 4. Results of PCA ordination showing patterns of variability among the 230 species recorded

\subsection{Challenges and way forward}

In developing countries with poor access to health facilities like Cameroon, medicinal plants are the richest and most available sources for drug discovery. In such situation when our societies are desperate to discover cures for new and deadly disease like COVID-19, the contribution of herbal medicine in early response strategies should be promoted. Though the country's pharmaceutical potentials are immense, constraints and challenges however exist at all levels. To effectively address these shortcomings, a strong political-will and support of the Cameroonian government will be highly needed. 


\section{Research and development}

Research in ethnobotany, ethnopharmacology and bioactive components of medicinal plants of Cameroon has been ongoing for quite some time by Universities' laboratories, by the Institute of Medical Research and Medicinal Plants Studies (IMPM) and by independent researchers. However, a systematic and concerted approach to this activity has been lacking. Much of these researches have been mainly academic and the concept of applied research in plant-based drug development has not received much attention. Although enough have been done in propagation of medicinal plants, research in support of industrial development, appropriate processing technologies to improve quality and yield, new formulations to new products and the marketing of finished products is still poorly developed. Actually, many medicinal plants sourced from Cameroon were involved in patents, most of which are owned by foreign entities.

Capacity building and financial support are a necessity at all level in order to stimulate active research on natural medicinal products at the local level. Specifically, efforts have to be geared towards developing and sponsoring applied research on natural products and drug discovery. It is in deed paradoxal that with the country's medicinal plant potentials, herbal drug discovery has not yet reached the expected performance.

\section{Capacity building}

One of the main problems facing the use of herbal medicines is the proof requirement of their usefulnes, safety and effectiveness. Unfortunately, research and training activities for traditional medicine practitioners has not received due support and attention. As a result, the quantity, quality, the safety and the efficacy of their herbal preparations are far from sufficient to meet the demands. These weaknesses could be 
corrected by capacity building and low-cost technologies for the industrial production of traditional medicines to make them more effective, stable, reproducible, controlled, and in galenic forms that can easily be transported. Capacity building will be vital for also organizing the corporation and integrating their practices into the perspectives of modern research and development continuum. By so doing, the indiscriminate sale and advertisement of herbal products in all forms of media without compliance to the existing regulations would be discouraged.

\section{Conservation of medicinal plants and documentation of available knowledge on}

\section{their use}

In face of the current risk of deforestation and degradation, conservation of medicinal plants must be a central focus. In this regard, one of the challenges is the lack of complete and conserved knowledge repository on the national pharmacopoeia and the immense medicinal metabolite diversity among these plants. Such a tool will be vital in providing the scientific community with comprehensive knowledge about metabolite data generation and exploitation in early response strategy to emerging diseases. Because of the growing environmental degradation and the rapid loss of the natural habitat for some of these plants due to anthropogenic activities, it is becoming increasingly urgent to reinforce medicinal plants conservation and documentation of their uses.

To ensure the sustainability of the resource base, conservation measures for medicinal plants will also be required for continuity of research, development and commercialization of natural medicinal products to address potential risk of overexploitation that may result from excessive commercialization and unsustainable practices. The effectiveness of the future sustainability of local natural ecosystems that harbours these medicinal plants will depend upon conservation management 
approaches that value the importance of involving local communities. In this light, there are lessons learned from Prunus africana management in the Mount Cameroon area that can fuel the step forward is the establishment of such medicinal plant conservation strategy.

The ratification by Cameroon of the Nagoya protocol on access to genetic resource and benefit sharing opens new and promising avenues to achieve the objectives of conserving the local medicinal plants, ensuring their sustainable utilization and improving their contribution in livelihoods improvement and economic development.

\section{Encouraging private sector involvement in herbal drug development}

There has so far been only very poor participation of the local private pharmaceutical industries in the field of herbal drug development in Cameroon. There should be incentives developed to attract and stimulated their investment in traditional medicine research, development and commercialization.

\section{Conclusion}

The purpose of this stock-taking study was to provide a preliminary review on Cameroonian medicinal plants with potentials to be evaluated and developed as remedy for the management of COVID-19. It appears that the country's medicinal plants potentials is immense and is a promising resource from a perspective of novel drug development against this pandemic. Based on the present findings it can be concluded that medicinal plants can be promising resources for the management of COVID-19 in African herbal medicine in general and Cameroon in particular.

Despite the great potential of local medicinal plants, it is unfortunate that they are still pejoratively refered to as "grand-mother recipes". More than ever, there is a need for 
applied research to provide more scientific evidence for the efficacy, to establish the standard formulation using the preliminary check list presented in this review and further clinical studies as part of the response strategy for the management of COVID19.

\section{Declaration of Competing Interest}

The authors declare that they have no competing interests.

\section{Funding}

The authors declare that they did not receive any funding for carrying out this research. 


\section{References}

Abonyi DO, Adikwu MU, Esimone CO, Ibezim EC (2009) Plants as sources of antiviral agents. Afr J Biotechnol; 8 (17), 3989-3994.

Adem S, Eyupoglu V, Sarfraz I, Rasul A, Ali M. (2020) Identification of Potent COVID-19 Main Protease (Mpro) Inhibitors from Natural Polyphenols: An in Silico Strategy Unveils a Hope against Corona. Preprints. DOI: 10.20944/preprints202003.0333.v1. Available from: https://www.researchgate.net/publication/340095736_Identification_of_Potent_COVID 19 _Main_Protease_Mpro_Inhibitors_from_Natural_Polyphenols_An_in_Silico_Strateg y_Unveils_a_Hope_against_CORONA [accessed Apr 21 2020].

Adu F, Apenteng J.A, Akanwariwiak WG, Sam GH, Ntinagyei Mintah D, Bortsie EB (2015) Antioxidant and in-vitro anthelminthic potentials of methanol extracts of barks and leaves of Voacanga africana and Rauwolfia vomitoria. Afr J Microbiol Res. 2015; 9(35): 1984-1988.

Agbedahunsi JM, Elujoba AA, Makinde JM, Oduda AMJ. (1998) Antimalarial Activity of Khaya grandifoliola Stem-bark, Pharm Biol. 1998; 36(1): 8-12.

Agbor GA, Kuate D, Oben JE(2007) Medicinal plants can be good source of antioxidants: Case study in Cameroon. Pakistan Journal of Biological sciences 10 (4), 537-550

Akram M, Shahab-Uddin, Ahmed A, Usmanghani K, Hannan A, Mohiuddin E Asif, M (2010) Curcuma longa and curcumin: a review article. Roman Journal of Biology. Plant Biology., 55 (2), 65-70.

Alamgeer Younis W, Asif H, Sharif A, Riaz H, Bukhari IA, Assiri AM (2018) Traditional medicinal plants used for respiratory disorders in Pakistan: a review of the ethnomedicinal and pharmacological evidence. Chin Med. 2018; 13:48. 
Alowanou GG, Olounlade AP, Azando1 EV, Dedehou VFGN, Daga FD, Hounzangbeadote SM (2015) A review of Bridelia ferruginea, Combretum glutinosum and Mitragina inermis plants used in zootherapeutic remedies in West Africa: historical origins, current uses and implications for conservation. J Appl Biosc. 2015; 87: 8003-8014.

Amoa Onguéné P, Ntie-Kang T, Likowo Lifongo L, Ndom N, Sippl W, Meva'a Mbaze L (2013) The potential of anti-malarial compounds derived from African medicinal plants, part I: a pharmacological evaluation of alkaloids and terpenoids. Malar J. 2013. 2013, 12: $449,25 p$.

Anywar G, Kakudidi E, Byamukama R, Mukonzo J, Schubert A, Oryem-Origa H (2020) Data on medicinal plants used by herbalists for boosting immunity in people living with HIV/ AIDS in Uganda. Data in Brief 29. 2020. April 2020, 105097.

Arbonnier M (2019) Arbres, arbustes et lianes d'Afrique de l'Ouest. Quatrième édition. Éditions Quae-Cirad. 2019.

Asante-Kwatia E, Yeboah Mensah A, Frimpong Baidoo M (2020) Analgesic and AntiInflammatory Effect of Ghanaian Medicinal Plants. In Intec open Eds. Medicinal Plants - Use in Prevention and Treatment of Diseases. 2020.

Asongalem E.A, Foyet HS, Ekobo S. Dimo T, Kamtchouing P (2004) Antiinflammatory, lack of central analgesia and antipyretic properties of Acanthus montanus (Ness) T. Anderson. J Ethnopharmacol. 2004;95(1):63-8.

Azantsa Kingue GB, Djuikoo Nouteza I, Kuikoua Tchetmi W, Takuissu G, Ngondi JL, Oben J (2017) Phytochemical Screening and Anti-diabetic evaluation of Citrus sinensis Stem Bark Extracts. Int J Biochem Res \& Rev. 2017. 17(2): 1-13.

Bogninou GSR, Bigo Agadaba PH, Gnanwe M, Agbangnan DCP, Chabi NW, Yedomonhan H, Avlessi F (2018) Phytochemical Composition and Antioxydant Capacity of 
Abelmoschus esculentus 1. Fresh Immature Fruits. Am J Food Sci Technol. 2018; 6 (5): $223-227$.

Chah KF, Muko KN, Oboegbulm SI (2000) Antimicrobial activity of methanolic extract of Solanum torvum fruit. Fitoterapia. 2000; 71 (2): 187-189.

Chen Z, Nakamura T (2004) Statistical evidence for the usefulness of Chinese medicine in the treatment of SARS. Phytotherapy Research. 2004;18(7): 592-4.

Chinsembu K.C., Hedimbi M (2010) An ethnobotanical survey of plants used to manage HIV/AIDS opportunistic infections in Katima Mulilo, Caprivi region, Namibia. $J$ Ethnobiol Ethnom. 2010; 6:25.

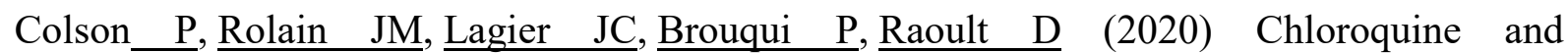
hydroxychloroquine as availabL weapons to fight COVID-19. Int $J$ Antimicrob $A g .2020 ; 4: 105932$.

Crtv 2020. COVID-19 : Archbishop Samuel Kleda proposes a herbal remedy. Retreived on http://www.crtv.cm/2020/04/COVID-19-archbishop-samuel-kleda-proposes-a-herbalremedy/, 29 April 2020.

Curbelo J, Luquero Bueno S, Galva Roman JM, Ortega-Gomez M, Rajas O, FernandezJimenez G, Vega-Pirisi L, Rodriguez-Salvanes F, Arnalich B, D1'az A, Costa R, de la Fuente H, Lancho A, Suarez C, Ancochea J, Aspa J (2017) Inflammation biomarkers in blood as mortality predictors in community-acquired pneumonia admitted patients: Importance of comparison with neutrophil count percentage or neutrophil-lymphocyte ratio. PLoS ONE. 2017; 12(3): e0173947.

Damrongkiet A, Svasti J Kittakoop P, khachonwut DP, Tanticharoen M, Thebtaranonth, Y (2002) Antiviral isoflavonoid sulfate and steroidal glycosides from the fruits of Solanum torvum. Phytochemistry. 2002; 59 (4): 459-463 
Dibong DS, Mvogo OBP, Vandi D, Ndjib RC, Tchamaha MF, Mpondo, ME (2015) Ethnobotanique des plantes médicinaLs anti hémorroïdaires des marchés et villages du Centre et du Littoral Cameroun. J Appl Biosc. 2015; 96: 9072 - 9093.

DU Hong-Zhi, HOU Xiao-Ying, MIAO Yu-Huan, HUANG Bi-Sheng, LIU Da-Hui (2020) Traditional Chinese Medicine: an effective treatment for 2019 novel coronavirus pneumonia (NCP) [J]. Chin J Nat Med, 2020, 18(3): 206-210.

ECDC 2020. COVID-19 (2020) Situation update worldwide, as of 10 august 2020. Retreived from https:/www.ecdc.europa.eu/en/geographical-distribution-2019-ncovcases, on October 30, 2020.

Elion Itou RDG, Sanogo R, Etou Ossibi AW, Nsondé Ntandou FG, Ondelé R, Pénem BM, Okiémy Andissa N, Diallo D, Ouamba JM, Abena AA (2014) Anti-Inflammatory and Analgesic Effects of Aqueous Extract of Stem Bark of Ceiba pentandra Gaertn. Pharmacol Pharmacy. 2014; 5: 1113-1118.

Etame-L G, Ngoul CC, Mbome B, Kidik PC, Ngene JP, Yinyang J, Ebongue OC, Ngaba GP, Dibong DS (2018) Contribution à l'étude des plantes médicinaLs et Lurs utilisations traditionnelLs dans L département du Lom et Djerem (Est, Cameroun). J Anim Pl Sci. 2018; 35 (1): 5560-5578.

Faheem Khan M, Khan MA, Khan ZA, Ahamad T, Ansari WA (2020) Identification of Dietary Molecules as Therapeutic Agents to Combat COVID-19 Using Molecular Docking Studies. Res Square Preprint. 2020; 20p.

Fogue Kouam S, Kusari S, Lamshöft M, KamgueTatuedom O, Spiteller M. Sapelnins G-J, acyclic triterpenoids with strong anti-inflammatory activities from the bark of the Cameroonian medicinal plant Entandrophragma cylindricum. Phytochemistry. 2012; 83 : 79-86. 
Fongnzossie EF, Tize Z, Fogang Nde PJ, Nyangono Biyegue CF, Bouelet Ntsama IS, Dibong SD, Nkongmeneck BA (2017) Ethnobotany and pharmacognostic perspective of plant species used as traditional cosmetics and cosmeceuticals among the Gbaya ethnic group in Eastern Cameroon. S Afr J Bot. 2017 ; 112: 29-39.

Fongod AGN, Modjenpa NB, Veranso MC (2013) Ethnobotany of Acanthaceae in the Mount Cameroon region. J Med Pl Res. 2013; 7(38) : 2859-2866.

Foyet HS, Tsala DE, Zogo Essono Bodo JC, Azanfack Name C, Toussoumna HL, Oben Eyong K (2015) Anti-inflammatory and anti-arthritic activity of a methanol extract from Vitellaria paradoxa stem bark. Pharmacog Res. 2015; 7(74): 367-377.

Gardini F, Belletti N, Ndagijimana M, Guerzoni ME, Tchoumbougnang F, Amvam Zollo, PH, Claudio Micci C, Rosalba Lanciotti R, Kamdem SLS (2009) Composition of four essential oils obtained from plants from Cameroon, and their bactericidal and bacteriostatic activity against Listeria monocytogenes, Salmonella enteritidis and Staphylococcus aureus. Afr J Microbiol Res. 2009; 3(5): 264-271.

Goothy SSK, Goothy S, Choudhary A, Potey GG, Chakraborty H, Kumar AHS, Mahadik VK (2020) Ayurveda's Holistic LifestyL Approach for the Management of Corona virus disease (COVID-19): Possible Role of Tulsi. Int j Res Pharm Sci. 2020; 1: 16-18.

Gounoue KR, Noukeu KBA, Tsakem NMJ, Youmsi FD, Ngueguim TF, Dzeufiet DPD, Dimo T, Penlap BV (2019) Anti-inflammatory potential of Tapinanthus globiferus (Loranthaceae) leaves as an alternative treatment against arthritis. The Journal of Phytopharmacology. 2019; 8(3): 96-103.

Huang C, Wang Y, Li X, Ren L, Zhao J, Hu Y et al (2020) Clinical features of patients infected with 2019 novel coronavirus in Wuhan, China. Lancet 2020. Doi: 10.1016/S0140-6736(20)30183-5. 
Iqbal S, Younas U, Chan KW, Zia-Ul-Haq M, Ismail M (2020) Chemical Composition of Artemisia annua L. Leaves and Antioxidant Potential of Extracts as a Function of Extraction Solvents. Molecules. 2012; 17: 6020-6032.

Isemura M (2019) Catechin in Human Health and Disease. Molecules. 2019; 24: 528; doi:10.3390/molecules24030528.

Ismail AB, Mohamed EA, Marghany MR, Abdel-Motaal FF, Abdel-Farid IB, d El-Sayed, MA (2014) Preliminary phytochemical screening, plant growth inhibition and antimicrobial activity studies of Faidherbia albida legume extracts. Journal of the Saudi Society of Agricultural Sciences. 2014; 15: 112-117.

Jassim SA, Naji MA (2003) Novel antiviral agents: a medicinal plant perspective. J Appl Microbiol. 2003; 95(3): 412-27.

Jiofack T, Fokunang C, Kemeuze V, Fongnzossie E, Tsabang N, Nkuinkeu, R., and Mapongmetsem, P.M( 2008) Ethnobotany and phytopharmacopoea of the SouthWest ethnoecological region of Cameroon. J Med Pl Res. 2008; 2(8): 197-207

Jiofack TR, Ayissi I, Fokunang C, Guedje N, Kemeuze V (2009) Ethnobotany and phytomedicine of the upper Nyong valley forest in Cameroon. Afr J Pharm Pharmacol. 2009; 3(4): 144-150.

Jossang A, Pousset JL, Bodo B (1994) Combreglutinin, a hydrolyzable tannin from Combretum glutinosum. J Nat Prod. 1994; 55(6): 732-737.

Kamatou GPP, Vermaak I, Viljoen AM (2011) An updated review of Adansonia digitata: A commercially important African tree. S Afr J Bot. 2011; 77:908-919.

Kamtchueng MO, Balyan R, Mouokeu RS, Tume C, Banerjee C, Chawla SA, Oumar M, Kuiate JR (2017) Anti-Inflammatory Activity of Methanol Extract and Fractions from Alchemilla kiwuensis Engl. on LPS Activated Macrophages. Int J Pharmacog Phytochem Res. 2017; 9(4): 473-481. 
Kaur M, Singh J, Mirza A (2018) Pharmacological and Medicinal Properties of Psidium guajava: A Review. Res J Chem Env Sci. 2018; 6 (4): 70-73.

Keyaerts E, Vijgen L, Pannecouque C, Van Damme E, Peumans W, Egberink H, Balzarini J, Van Ranst M (2007) Plant Lctins are potent inhibitors of coronaviruses by interfering with two targets in the viral replication cycle. Antivir Res. 2007; 75: 179-187.

Khaerunnisa S, Kurniawan H, Awaluddin R, Suhartati S, Soetjipto S (2020) Potential Inhibitor of COVID-19 Main Protease (Mpro) From Several Medicinal Plant Compounds by Molecular Docking Study. Preprints. ;2020, 2020030226.

Khalifa I, Zhu W, Nafie MS, Dutta K, Li C (2020) Anti-COVID-19 effects of ten structurally different hydrolysable tannins through binding with the catalytic-closed sites of COVID-19 main protease: An in-silico approach. AvailabL from: https://www.researchgate.net/publication/339999895_Anti-COVID-

19_effects_of_ten_structurally_different_hydrolysabL_tannins_through_binding_1_wit h_the_catalytic-closed_sites_of_COVID-19_main_protease_An_in-silico_approach_2 [accessed Apr 21 2020]. 2020.

Khodadadi S (2015) Role of herbal medicine in boosting immune system. Immunopathol Persa. 2015; 1(1): e01.

Klimek-Szczykutowicz M, Szopa A (2020) Ekiert H. Citrus limon (Lmon) Phenomenon-A Review of the Chemistry, Pharmacological Properties, Applications in the Modern Pharmaceutical, Food, and Cosmetics Industries, and Biotechnological Studies. Plants. 2020; 9: 1-24.

Kuate JR (2015) Immunomodulatory activity of methanol Laf extracts of Cameroonian medicinal plants. J Compl Integr Med. 2015; 12(4): 267-275.

Kuete V, Efferth T (2010) Cameroonian medicinal plants: pharmacology and derived natural products. Front Pharmacol. 2010; doi: 10.3389/fphar.2010.00126 
Kuete V, Sipowo VR, Mbaveng AT, Cândida da Silva V, Rodrigues CM, Nkengfack AE, Campaner dos Santos L, Vilgas W, Efferth T (2018) Catechin Derivatives from Parkia biglobosa Displayed SeLctive Cytotoxicity Towards Lukemia CCRF-CEM Cell Line and its PGlycoprotein Expressing Subline CEM/ADR5000. Invest Med Chem Pharmacol. 2018; 1(1): 1 - 5.

Lai CC, Shih TP, Ko, WC, Tang HJ, Hsueh PR (2020) Severe acute respiratory syndrome coronavirus 2 (SARS-CoV-2) and coronavirus disease-2019 (COVID-19): The epidemic and the challenges. Int J Antimicrob Ag. 2020; 5(2020) : 105924.

Le Point International, 2020. Au Mexique, des amulettes contre le coronavirus. Retreived from https://www.lepoint.fr/monde/au-mexique-des-amulettes-contre-lecoronaviru-23-032020-2368294_24.php, 23march 2020.

Lelesius R, Karpovaitė A, Mickienė R, Drevinskas T, Tiso N, Ragažinskienė O, Kubilienė L, Maruška A, Šalomskas A (2019) In vitro antiviral activity of fifteen plant extracts against avian infectious bronchitis virus. BMC Veter Res. 2019; 15:178.

Liu C, Zhou Q, Li Y, Garner LV, Watkins SP, Carter LJ, Smoot J, Greg AC, Daniels AD, Jervey S, Albaiu D (2020) Research and Development on Therapeutic Agents and Vaccines for COVID-19 and Related Human Coronavirus Diseases. : ACS Cent Sci. 2020; 6: 315-331.

Lu H (2020) Drug treatment options for the 2019-new coronavirus (2019-nCoV). Biosci Trends. 2020, doi:10.5582/bst.01020.

Mahomoodally MF (2013) Traditional Medicines in Africa: An Appraisal of Ten Potent African Medicinal Plants. Evidence-based Complementaryand Alternative Medicine. Special Issue on Recent Advances towards Validating Efficacy and Safety of African Traditional Medicines. 2013. https://doi.org/10.1155/2013/617459. 
Mambe FT, Voukeng IK, Beng VP, Kuete V (2016) Antibacterial activities of methanol extracts from Alchornea cordifolia and four other Cameroonian plants against MDR phenotypes. J Taibah Univ Med Sci. 2016; 11(2): 121-127.

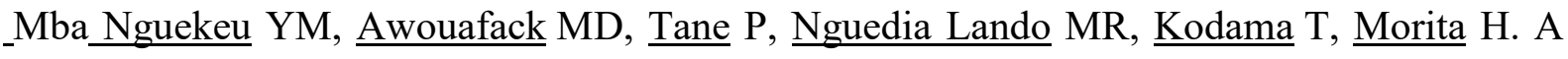
kaempferol triglycoside from Tephrosia preussii Taub. (Fabaceae). Nat Prod Res. 2017; $31(\underline{21})$.

Mbaveng TA, Kuete V, Mapunya MB., Beng PV, Nkengfack EA, Meyer MJJ, Lall, N (2011) Evaluation of four Cameroonian medicinal plants for anticancer, antigonorrheal and antireverse transcriptase activities. Environ Toxicol Pharmacol. $2011 ; 32(2): 162-167$.

Midi-Madagascar (2020). «COVID-Organics » : La communauté scientifique sort du silence.

Retrieved from http://www.midi-madagasikara.mg/COVID-19/2020/04/22/COVIDorganics-la-communaute-scientifique-sort-du-silence/, 22 april 2020.

Ming LC (1999) Ageratum conyzoides: A tropical source of medicinal and agricultural products. In: J. Janick (ed.), Perspectives on new crops and new uses. ASHS Press, Alexandria, VA, pp 469-473.

Moghadamtousi SZ, Kadir HA, Hassandarvish P, Tajik H, Abubakar S, Zandi K (2014) A Review on Antibacterial, Antiviral, and Antifungal Activity of Curcumin. BioMed Research International Volume 2014, Special issue on Biologic Activity and Biotechnological Development of Natural Products. Hindawi Publishing Corporation, 12 pages.

Mohal DS, Dewani AP, Chandewar AV, Khadse CD, Tripathi AS, Agrawa SS (2009) Brief review on medicinal potential of Terminalia catappa. J Herb Herbal Med Toxicol. 2009; 3 (1): 13-17. 
Mohamad M, Ali MW, Ahmad A (2010) Modelling for extraction of major components from Eurycoma longifolia. J Appl Sci. 2010; 10(21): 2572-2577.

Mohammadi N, Shaghaghi N (2020) Inhibitory Effect of Eight Secondary Metabolites from Conventional Medicinal Plants on COVID_19 Virus Protease by MoLcular Docking Analysis. ChemRxiv. Preprint. https://doi.org/10.26434/chemrxiv.11987475.v1. 2020.

Mokale Kognou AL, Kowa TK, Pateriya P, Pal NP, Mouokeu RS, Tchinda Tiabou A, Agbor Agbor G, Singh RP, Ngono Ngane RA (2020) Pharmacological evidence of Vitex thyrsiflora, Entandrophragma cylindricum, and Anonidium mannii used forthe management of inflammation in Cameroon. J Basic Clin Physiol Pharmacol. 2020; $2020 ; 20190053$.

Mokale Kognou, AL, Ngono Ngane RA, Pawar RS, Pateriya, P, Pal PN, Ebelle Etame RM, Tiabou Tchinda A, Agbor Agbor G, Kumar S, Mouokeu RS, Sone Mouelle A, Enguehard Gueiffier S (2017) Anti-Inflammatory Activity and Bioavailability Profile of Ethanolic Extract of Dichaetanthera africana. Pharmacologia. 2017; 8 (1): 32-40.

Mokondjimobe E, Joe MB, Barkha S, Dzeufiet, PD, Chenal H, Otsudi'andjeka JB, Bipolo S, Besse M, Mamadou G, Nzouzi NL, Kamtchouing P, Meddah B, Okpwae Okpwae J, Schobiltgen F, Eto B (2012) Fagaricine, a new immunorestorative phytomedicine from Zanthoxylum heitzii: Preclinical and multicenter cohort clinical studies based on HIVinfected patients in six countries. Phytopharmacology. 2012. 2(1): 26-45.

Moradi MT, Karimi A, Lorigooini Z (2017) Alkaloids as the natural anti-influenza virus agents: a systematic review, Toxin Reviews. 2017. DOI: 10.1080/15569543.2017.1323338.

Mounguengui S, Saha Tchinda JB, Ndikontar MK, Dumarçay S, Attéké C, Perrin D, Gelhaye G, Gérardin P (2016) Total phenolic and lignin contents, phytochemical screening, 
antioxidant and fungal inhibition properties of the heartwood extractives of ten Congo Basin tree species. Ann For Sci. 2016; 73 (2), 287-296.

Muhoya FK, Kadima JN, Ranarivelo N, Frédérich M, Hubert P, Djang'eing'a RM (2017) Preliminary Phytochemical Content and Antidiabetic Potential Investigations of Panda oleosa (Pierre) Used in Kisangani Areas. AM J of Anal Chem. 2017; 8: 564-581.

Mutalik S, Paridhavi K, Mallikarjuna Rao C, Udupa N (2003) Antipyretic and analgesic effect of leaves of Solanum melongena Linn. In rodents. Ind J of Pharmacol. 2003; 35: 312315.

Ndam LM, Mih AM, Fongod AGN, Tening AS, Tonjock RK, Enang JE, Fujii Y (2014) Phytochemical screening of the bioactive compounds in twenty (20) Cameroonian medicinal plants. Int J Curr Microbiol Appl Sci. 2014; 3(12):1-11.

Ngono Ngane RA, Koanga Mogtomo ML, Tchinda Tiabou A, Magnifouet Nana H, Motso Chieffo PR, Mballa Bounou Z, Ebelle Etame RM, Ndifor F, Biyiti L, Amvam Zollo PH (2011) Ethnobotanical survey of some Cameroonian plants used for treatment of viral diseases. Afr J of Pl Sci. 2011; 5(1): 15-21.

Ngouela S, Tsamo E, Connolly JD (1994) Lignans and other constituents of Zanthoxylum heitzii. Phytochemistry. 1994; 37(3): 867-869.

Ngoupayo J, Ebene Moukoury, AM, Mushagalusa Kasali F, Kourouma K, Ntsama Essomba, C (2018) Preliminary phytochemical screening and antimicrobial evaluation of leaves and barks extracts from Cola anomala (Schott and Endlicher) Journal of Pharmacognosy and Phytochemistry. 2018; 7(5): 2262-2266.

Noumedem JAK, Mihasan M, Lacmata ST, Stefan M, Kuiate JR, Kuete, V (2013) Antibacterial activities of the methanol extracts of ten Cameroonian vegetabLs against Gram-negative multidrug-resistant bacteria. BMC Complementary and Alternative Medicine. 2013; 13, 26. 
Noumi N, Manga PN (2011) Traditional medicines for HIV/AIDS and opportunistic infections in North-West Cameroon: case of skin infections. Amer J Trop Med Pub Health. 2011; 1(3): 44-64.

Ntie-Kang F, Likowo Lifongo L, Meva'a Mbaze L, Ekwelle N, Owono Owono LC, Megnassan E, Judson PN, Sippl W, Efange SMN (2013) Cameroonian medicinal plants: a bioactivity versus ethnobotanical survey and chemotaxonomic classification. $B M C$ Compl Alter Med. 2013; 13: 147.

Oguntibeju OO (2018) Medicinal plants with anti-inflammatory activities from selected countries and regions of Africa. J Infl Res. 2018; 11: 307-317.

Ogunwande I, Avoseh ON, Igile DO, Lawal OA, Ascrizzi R, Guido F (2019) Chemical Constituents, Anti-nociceptive and Anti-inflammatory Activities of Essential Oil of Phyllanthus muellerianus. Nat Prod Com. 2019; 1-7.

Oumar M, Tume C, Kamanyi A (2010) Immunostimulation by Stem Barks of Pseudocedrela kotschyi (Family: Meliaceae): Stimulation of Phagocytosis Activities of Macrophages and Proliferative Response of Lymphocytes by Aqueous, Methanol and Hexane Extracts. Int J Sci Eng Res. 2010; 8 (11).

Packman EW, Abbott DD, Harrisson, JW. A preliminary study of the pharmacology of 11desmethoxyreserpine (raunormine) an alkaloid from Rauwolfia canescens. $J \mathrm{Am}$ Pharma Ass. American Pharmaceutical Association, 2006; 45(2 Part 1): 89-93.

Pone Kamdem B (2017) “Advances on Ethnomedicinal Uses, Phytochemistry, and Pharmacology of Spathodea campanulata P. Beauv". EC Pharmacology and Toxicology. 2017; 5(2): 51-62.

Poudel Adhikari S, Meng S, Wu Y, Mao Y, Ye R, Wang Q, Sun C, Sylvia S, RozelL S, Raat H, Zhou HA (2020) Literature Review of 2019 Novel Coronavirus During the Early 
Outbreak Period: Epidemiology, Causes, Clinical Manifestation and Diagnosis, Prevention and Control. Preprints. 2020; 77-137.

Prompetchara E, Ketloy C, Palaga T (2020) Immune responses in COVID-19 and potential vaccines: Lessons learned from SARS and MERS epidemic. Asian Pac J Allergy Immunol. 2020; 38:1-9.

Rahmani AH, Almatroudi A, Alrumaihi F, Khan AA (2018) Pharmacological and therapeutic potential of neem (Azadirachta indica). Phcog Rev. 12: 250-255.

Rhazri KS, Hamri M, Lbri R, Onguén H, Ouchetto A, Hafid M, Izikki, Khouili M (2015) Isolation of 3,5,7,4'-Tetrahydroxyflavone (Kaempferol) from the methanol extract of the Laves of Cassia alata and in-vitro evaluation of its potential inhibitory effect on the human pulmonary arterial hypertension (PAH). Der Pharma Chemica. 2015; 7(7): 241245.

Sadeer BN, Llorent-Martínez EJ, Bene K, Fawzi Mahomoodally M, Mollica A, Ibrahime Sinan K, Stefanucci A, Ruiz-Riaguas A, Fernández-de Córdova ML, Zengin G (2019) Chemical profiling, antioxidant, enzyme inhibitory and molecular modelling studies on the leaves and stem bark extracts of three African medicinal plants. J Pharm Biomed Anal. 2019; 10(174): 19-33.

Sagnia B, Fedeli D, Casetti R, Montesano C, Falcioni G, et al (2014) Antioxidant and Anti Inflammatory Activities of Extracts fromCassia alata, Eleusine indica, Eremomastax speciosa, Carica papaya and Polyscias fulva Medicinal Plants Collected in Cameroon. PLoS ONE. 2014; 9(8): e103999.

Saini S, Kaur H, Verma B, Singh, SK (2009) Kigelia africana (Lam.) Benth.—an overview. Nat Prod Rad. 2009; 8(2): 190-197. 
Sakah Kaunda J, Zhang YJ (2019) The Genus Solanum: An Ethnopharmacological, Phytochemical and Biological Properties Review. Nat Prod Bioprospect. 2019; 9 (2): $77-137$.

Sani I, Abdulhamid A, Bello F (2014) Eucalyptus camaldulensis: Phytochemical composition of ethanolic and aqueous extracts of the leaves, stembark, root, fruits and seeds. J Sci Innov Res. 3(5): 523-526.

Sebua SS, Maroyi A (2013) Medicinal plants used for the treatment of tuberculosis by Bapedi Traditional healers in three districts of the Limpopo province, south Africa. Afr J Tradit Complement Altern Med. 2013; 10(2): 316-323.

Shafei NKA, Elshafie AE, Nour A (2016) Antitoxic, Antifungal and Phytochemical Analysis of Medicinal Compounds of Guiera senegalensis Leaves in Sudan. J Plant Biochem Physiol. 2016 ; 4: 166.

Shaghaghi N (2016) Molecular Docking study of novel COVID-19 Protease with low risk TerpenoidesCompounds of Plants. ChemRxiv. Preprint. Accessed on April 22, 2020.

Shakya, A.K (2016) Medicinal plants: Future source of new drugs. Int J Herb Med. 2020. 4(4): 59-64.

Sharma AD, Kaur I (2020) Jensenone from eucalyptus essential oil as a potential inhibitor of COVID 19 corona virus infection. Res Rev Biotechnol Biosc. 2020; 7(1): 59-66.

Sidjui Sidjui L, Melong R, Mahiou-Lddet V, Herbette G, Tiabou Tchinda A, Ollivier E, Ngosong Folefoc G (2015) Triterpenes and Lignans from Kigelia Africana. J Appl Pharma Sci. 2015; 5(2): 001-006.

Sputniknews (2020). Au Burkina Faso, Ls phytomédicaments de l'espoir contre L COVID19. Retrieved from https://fr.sputniknews.com/afrique/202004031043470136-auburkina-faso-Ls-phytomedicaments-de-Lspoir-contre-L-COVID-19/, 21 april 2020. 
Taghizadeh-Hesary F, Akbari H (2020) The Powerful Immune System Against Powerful COVID-19: A Hypothesis, Medical Hypotheses. 2020.

Taghreed AH, Murad AM, Mohamed AD, Saleh AQ (2017) Antiviral Activities of Capsicum annuum Methanolic Extract against Herpes Simplex Virus 1 and 2. Pakistan J Zool. $2017 ; 49(1): 267-272$.

Tala Sipowo, R.V., Wache Ouahouo, B.M., Djomkam Maza, H.L., Ishikawa, H., Nishino, H., Mkounga, P. Nkengfack, AE (2017) Triterpenes and Coumaroyltyramide from Ochthocosmus africanus. J Diseases Med Pl. 3(1): 12-16.

Tamo SP, Essama RSH, Etoa FX (2016) Plants used in Bandjoun village (La'Djo) to cure infectious diseases: An ethnopharmacology survey and in-vitro Time-Kill Assessment of some of them against Escherichia coli. The J Phytopharmacol. 2016; 5(2): 56-70.

Tatsimo SJN, Tamokou JdD, Havyarimana L. et al (2012) Antimicrobial and antioxidant activity of kaempferol rhamnoside derivatives from Bryophyllum pinnatum. BMC Res Notes 5, 158 (2012). https://doi.org/10.1186/1756-0500-5-158

Tchuenguem RT, Kechia FA, Kuiate JR, Dzoyem JP (2017) Ethnopharmacological survey, antioxidant and antifungal activity of medicinal plants traditionally used in Baham locality (Cameroon) to treat fungal infections. Arch Med Biomed Res. 2017; 3(2):91103.

Tene M, Tane P., Sondengam BL, Connolly JD (2004) Lignans from the roots of Echinops giganteus. Phytochemistry. 2004; 5(4): 2101-2105.

Tijani AY, Okhale SE, Salawu TA, Onigbanjo HO, Obianodo LA, Akingbasote JA, Salawu OA, Okogun JI, KunL FO, Emeje M (2009) Antidiarrhoeal and Antibacterial properties of crude aqueous stem bark extract and fractions of Parkia biglobosa (Jacq.) R. Br. Ex G. Don. Afr J Pharma Pharmacol. 2009; 3(7): 347-353. 
Tomar A (2017) Medicinal use of Abelmoschus esculentus (Linn.) Moench. (Bhindi) to cure fever. J Phcog Phytochem. 2017; 6(4): 596-597

Tsobou R, Mapongmetsem P-M, Voukeng KI, Van Damme P (2015) Phytochemical screening and antibacterial activity of medicinal plants used to treat typhoid fever in Bamboutos division, West Cameroon. J Appl Pharma Sce. 2015; 5 (06): 034-049.

Vellingiri B, Jayaramayya K, Iyer M, Narayanasamy A, Govindasamy V, Giridharan G, Ganesan S, Venugopal A, Venkatesan D, Ganesan H, Rajagopalan K, Pattanathu KSMR, Cho S, Kumar NS, Subramaniam MD (2020) COVID-19: A promising cure for the global panic. Sce Total Env. 2020 ; 725 (10) : 138277.

Yemele MD, Telefo PB, Lienou LL, Tagne SR, Fodouop CSP, Goka CS, Lmfacka MC, Moundipa FP (2014) Ethnobotanical survey of medicinal plants used for pregnant women's health conditions in Menoua division-West Cameroon. J Ethnopharmacol. $2014 ; 160: 14-39$

Yinyang J, Mpondo Mpondo E, Tchatat M, Ndjib RC, Mvogo Ottou PB, Dibong SD (2014) Les plantes à alcaloïdes utilisées par les populations de la ville de Douala (Cameroun). $J$ Appl Biosci. 2014; 78: 6600 - 6619.

Zhang X (1996). Traditional medicine and WHO. World Health No. 2, 2p.

Zhang D, Wu K, Zhang X, Deng S, Peng B (2020) In silico screening of Chinese herbal medicines with the potential to directly inhibit 2019 novel coronavirus. J Integr Med. $2020 ; 18: 152-158$.

Zumla A, Hui DS, Azhar EI, Memish ZA, Maeurer M (2020) Reducing mortality from 2019-nCoV: host-directed therapies should be an option. Correspondence $2020 ; 395$ (10224), PE35-E36. 
Figures

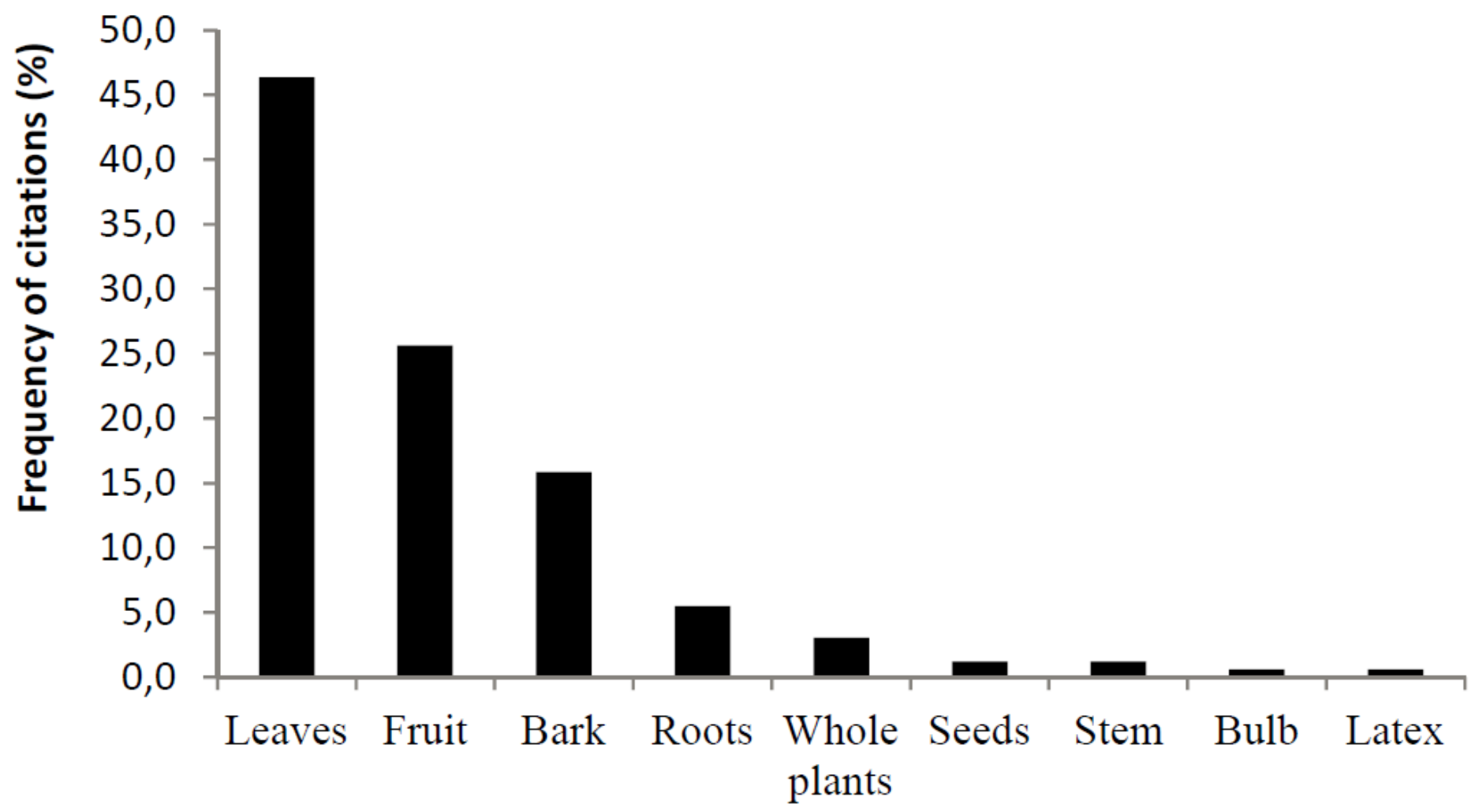

Figure 1

Frequency of plant parts used in management of COVID-symptoms 


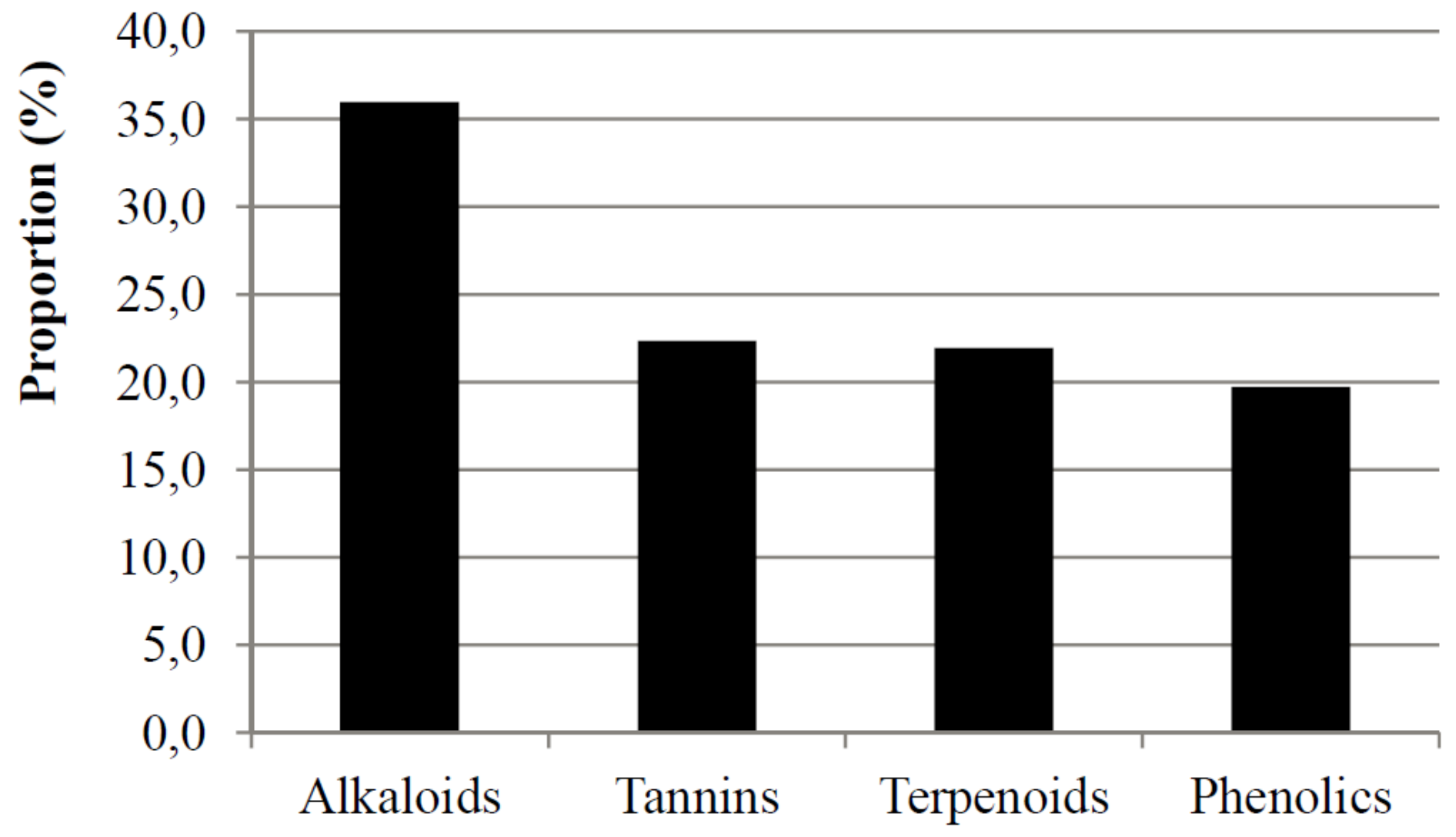

Figure 2

Distribution of secondary metabolites in the recorded plants

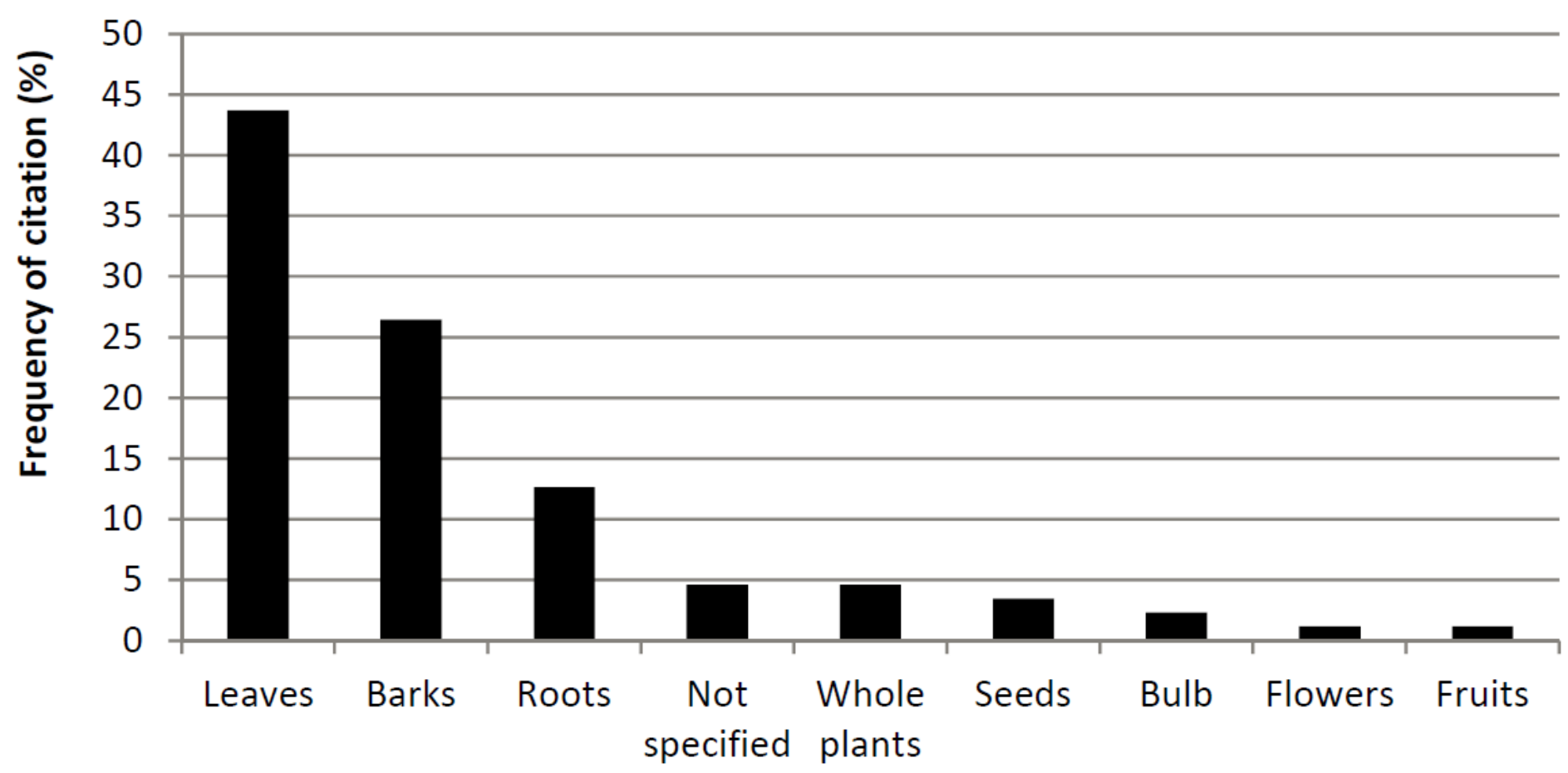

Figure 3 
Frequency distribution of plant parts with imunomodulatory, antiinflammatory or antiviral properties

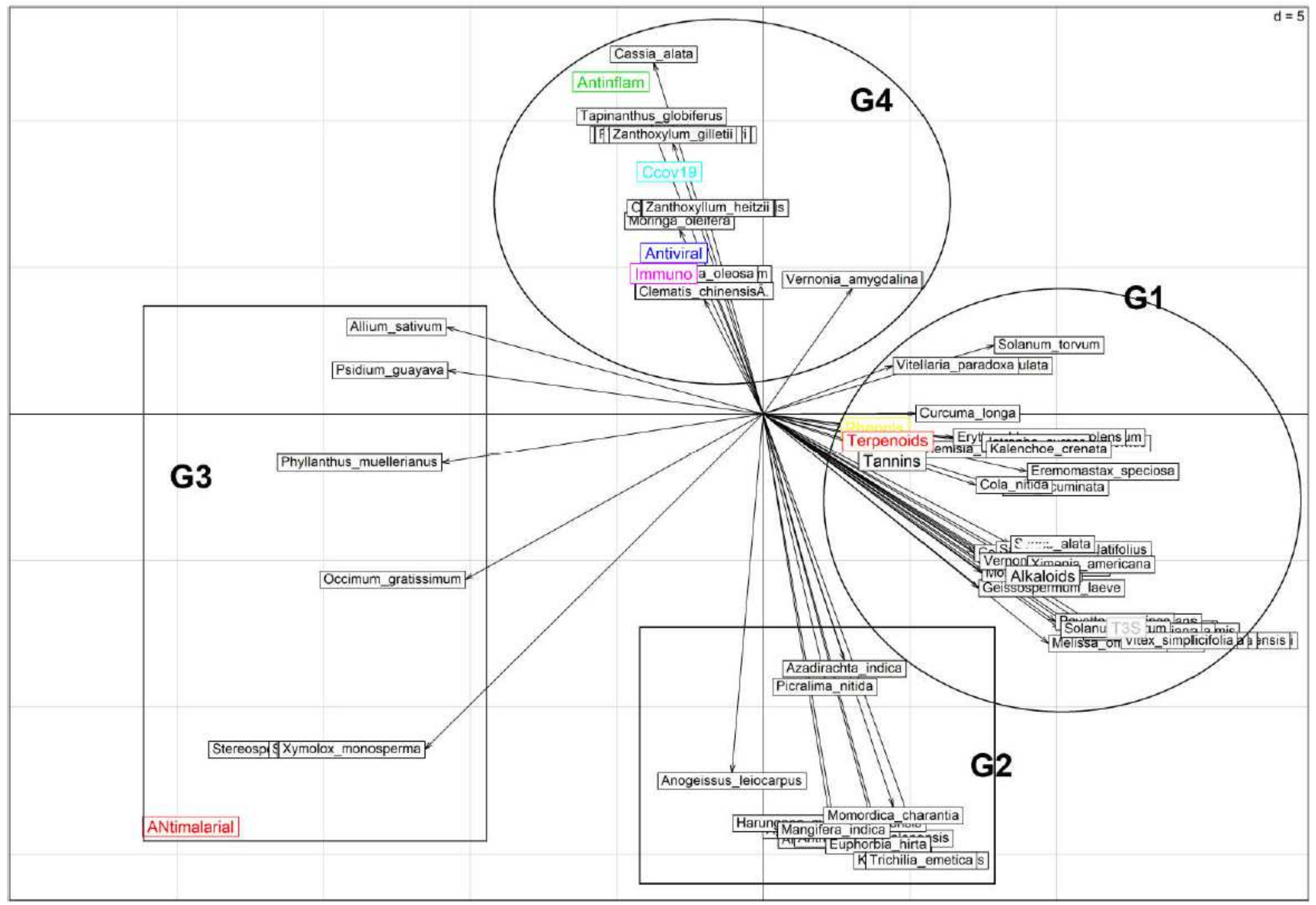

\section{Figure 4}

Results of PCA ordination showing patterns of variability among the 230 species recorded 